Beyond Essentialism: Cultural Differences in Emotions Revisited

Michael Boiger ${ }^{1}$, Eva Ceulemans ${ }^{1}$, Jozefien De Leersnyder ${ }^{1}$, Yukiko Uchida ${ }^{2}$, Vinai Norasakkunkit $^{3}, \&$ Batja Mesquita ${ }^{1}$

${ }^{1}$ University of Leuven, ${ }^{2}$ Kyoto University, ${ }^{3}$ Gonzaga University

This research was supported by a grant from the Research Council of the University of Leuven to Batja Mesquita and by a postdoctoral research fellowship from the Research Foundation - Flanders (FWO) to Michael Boiger

Michael Boiger, Eva Ceulemans, Jozefien De Leersnyder, \& Batja Mesquita, Faculty of Psychology and Educational Sciences, University of Leuven, Leuven, Belgium Yukiko Uchida, Kokoro Research Center, Kyoto University, Kyoto, Japan Vinai Norasakkunkit, Department of Psychology, Gonzaga University, Spokane, WA, USA

Correspondence concerning this article should be addressed to Michael Boiger or Batja Mesquita, Center for Social and Cultural Psychology, Department of Psychology, University of Leuven, Tiensestraat 102 - bus 3727, 3000 Leuven, Belgium. Email: $\underline{\text { michael.boiger@kuleuven.be or mesquita@kuleuven.be }}$

Revised version submitted on September 6, 2017 


\begin{abstract}
The current research offers an alternative to essentialism for studying cultural variation in emotional experience. Rather than assuming that individuals always experience an emotion in the same way, our starting point was that the experience of an emotion like anger or shame may vary from one instance to another. We expected to find different anger and shame experience types, that is, groups of people who differ in the instances of anger and shame that they experience. We proposed that studying cultural differences in emotional experience means studying differences in the distribution of these types across cultural contexts: There should be systematic differences in the types that are most common in each culture. Students from the United States, Japan, and Belgium $(N=928)$ indicated their emotional experiences in terms of appraisals and action tendencies in response to 15 hypothetical anger or shame situations. Using an inductive clustering approach, we identified anger and shame types who were characterized by different patterns of anger and shame experience. As expected, we found that the distribution of these types differed across the three cultural contexts: Of the two anger types, one was common in Japan and one in the U.S. I Belgium; the three shame types were each most prevalent in a different cultural context. Participants' anger and shame type was primarily predicted by their culture of origin (with an accuracy of $72.3 \%$ for anger and $74.0 \%$ for shame), and not, or much less, by their ethnic origin, SES, gender, self-construal, or personality.
\end{abstract}

(249/250 words)

Keywords: Culture, context, anger, shame, population thinking 


\section{Beyond Essentialism: Cultural Differences in Emotions Revisited}

An emotion like anger can be experienced in very different ways. Take the different ways Motoko, a Japanese PhD student, and Heather, her North American counterpart experience anger throughout a day. In this example, we simplify by assuming that Motoko and Heather encounter two similar events during one day. In the morning, they each present their research to their respective research groups. A few minutes into their respective presentations, one of the younger students in their labs starts ranting about how their study is largely irrelevant. Both are frustrated with the student's interruption and struggle to focus during the remainder of their presentation; however, while Heather also wonders what she could have done to make her argument more convincing, Motoko is appalled by her junior's

lack of respect. Heather's anger experience thus consists of a different pattern of appraisal and action tendencies (frustration, self-blame, and lack of focus) than Motoko's anger experience (which includes other-blame instead of self-blame). A few hours later, when Heather and Motoko are ready to cycle home, each finds out that the building's caretaker had their bikes removed because they did not park them inside the designated parking area. Heather curses at the caretaker's obsession with rules and keeps thinking how she would like to give him a piece of her mind - she had parked the bike just a few meters away from the parking area. In contrast, Motoko tells herself that she should have known better and keeps her frustration to herself. Here, Heather's anger experience consists of frustration, other-blame, and aggression, while Motoko's anger experience consists of frustration, self-blame, and non-action. In sum, the category of anger consists of different instances of emotional experience for Heather than for Motoko that day (see also Kuppens, Van Mechelen, Smits, De Boeck, \& Ceulemans, 2007).

Conceptualizing anger as a category of instances is a form of "population thinking" (Barrett, 2013, 2017a). Each instance within the population is constrained by the affordances 
and demands of the particular environment in which it occurs. The current research adopts this kind of population thinking into the study of cultural variation in emotions. Culturally different instances of emotions should occur because of culturally different meanings. For example, the ranting of a junior colleague afforded Motoko a culture-specific instance of anger because of the Japanese focus on hierarchy and respect. The same situation did not afford Heather a construal of anger in terms of hierarchy or respect, because these values simply do not penetrate social life in the (Northern) United States as much as they do in Japan. When cultural meanings consistently and systematically afford different instances of emotional experience, emotions correspond with different populations of instances across cultures. Important to population thinking is also that not every situation in Japan draws on hierarchy and respect concerns, and that moreover, some situations (for some people) in the United States do. This means that the populations of anger instances that Motoko and Heather experience, while forming a distinct pattern, can also overlap.

Adopting population thinking in the cross-cultural study of emotions means that we start from groups of people who share a way of experiencing emotions, or experience types. These experience types are themselves populations of instances of emotional experience. If Motoko represents an experience type, then this type is characterized by the anger experienced with a ranting junior colleague, the anger experienced upon the bike removal, and probably many other instances of anger. Cross-cultural research would ask the question how many (if any) individuals represent a certain experience type in each culture. For example, we would want to know if people who, like Motoko respond with frustration, lack of focus, and other blame, to the ranting student and with frustration, self-blame, and non-action to the towed bike, exist in the US and Japan; and also whether there are more people like Motoko in either culture. Hence, cross-cultural comparison of emotions is a comparison of people who represent experience types (i.e., populations of emotion instances). 
In this study, we probed emotional experience by measuring people's patterns of appraisal and action tendencies across a range of culturally relevant anger and shame situations in the U.S., Japan, and Belgium. ${ }^{1}$ Based on the concrete instances of appraisal and action tendency patterns that each participant reported, we inferred types of anger and shame experience. We used the distribution of these types to assess cultural differences in how anger and shame are experienced across the three cultures.

\section{A Novel Approach to Cultural Variation in Emotional Experience}

The current study forms a departure from the essentialist approach that has dominated much of the psychological thinking throughout the last century (Barrett, Mesquita, \& Smith, 2010), including research on emotions. An essentialist approach assumes that "emotions" can be neatly defined and categorized into different, internally homogenous kinds. In this view, each emotion has a characteristic fingerprint, be it defined as a pattern of appraisals and action tendencies, or alternatively, a pattern of facial actions or autonomic nervous system changes. Just like fingerprints remain essentially unchanged but may vary slightly from one instance to another (because of the temperature of your skin, for instance), some random variation may occur in the patterns of characteristics for emotions (example taken from Barrett, 2017a). Yet in essence, emotional instances were treated as interchangeable and invariant. In our study, we started from a fundamentally different conception of emotions, and consider emotions like anger as populations of instances (Barrett, 2006, 2013, 2017a, 2017b).

Ironically, much of the research on cultural variation in emotion—our own previous research included—-has been guided by this essentialist approach (e.g., Boiger, Mesquita, Tsai, \& Markus, 2012; Imada \& Ellsworth, 2011; Mauro, Sato, \& Tucker, 1992; Mesquita, 2001; Scherer \& Wallbott, 1994). The question underlying many cross-cultural studies on emotions was whether similar emotions in different cultures (e.g., "anger" in the US and "anger" in Japan) were different essences or the same. In much of this research, emotions 
were described in terms of the average patterns of appraisals and/or action tendencies associated with them. For instance, Roseman and colleagues (1995) found that anger in India and anger in the United States, on average, were similarly characterized by an appraisal of other-blame, but in contrast to U.S. anger, Indian anger was more likely appraised as being caused by circumstances (for other examples, see Frijda, Kuipers, \& ter Schure, 1989; Imada \& Ellsworth, 2011; Mauro et al., 1992; Roseman et al., 1995; Scherer \& Wallbott, 1994).

However, our example from the beginning suggest that looking at the average emotional responses of Heather and Motoko across instances might veil cultural differences in their anger experiences. On average, both Heather and Motoko experienced comparable levels of other-blame, self-blame and frustration that day; the only difference to stand out would be Heather's greater tendency toward hostility. Yet, their anger experiences are clearly more different than that, and this would become clear when considering the different instances of anger. That is, cultural differences would be found when considering the situations in which certain anger experiences occur.

Some previous cross-cultural research has considered situational effects. However, these studies primarily focused on emotional intensity during a limited set of situational contexts, and were therefore limited in scope (e.g., Chentsova-Dutton \& Tsai, 2010; Tsai, Miao, Seppala, Fung, \& Yeung, 2007; Wallbott \& Scherer, 1986). The few studies that did explore cultural variation in how people appraise particular situations (Imada \& Ellsworth, 2011) or feel motivated to act upon them (Mesquita, 1993) investigated if people experience different categories of emotion when their appraisals/action tendencies differ-thereby still adopting an essentialist approach to emotions. For example, Imada and Ellsworth (2011) compared cultural differences in the emotions experienced after success. They found that American participants appraised success situations as caused by themselves and experienced pride, whereas Japanese appraised success situations as caused by circumstances and felt 
lucky. At the core of this research lies the assumption that an emotion category such as pride is characterized by a stable appraisal pattern (see Mesquita \& Ellsworth, 2001).

In the present study, we assume that variance is at the heart of the phenomenon of emotions. First, different instances of emotion may correspond to different patterns of appraisals and action tendencies. Depending on the constraints and affordances of the immediate environment, as perceived in a particular cultural context, anger might come with different patterns of appraisal and action tendencies (e.g., frustration, self-blame, other-blame, lack of focus, aggression, or non-action) (Barrett, Mesquita, Ochsner, \& Gross, 2007; Boiger \& Mesquita, 2012; Mesquita, 2010). Figure 1 shows how patterns of experience (bottom level) differ from instance to instance (middle level) according to the affordances and demands of the respective (cultural) environments. This is shown for both Heather and Motoko, whose exemplary anger instances that day are illustrated with both overlapping (rounded squares) and distinct (squares and circles) elements in their respective pattern of appraisals and action tendencies. Second, and as explained before, there are different experience types that represent different populations of instances. Figure 1 displays two different experience types (top level)—one type who experiences anger like Heather and one type who experiences anger like Motoko. Third, cultures may differ in the types that are most common (or exist at all). Figure 1 schematically displays the distribution of experience types for six participants from two different cultures (Heather, Motoko, and four other participants); in this case, the two types exist in both cultures, but vary in terms of which one is the most common. Therefore, and in contrast to previous research that treated within-culture variance as random (for an exception, see Eid \& Diener, 2001), the current approach turns variance in people's emotional experiences into the topic of investigation; this approach suggests that it is the distribution of situated patterns, and at a higher level the distribution of experience types, that varies systematically across cultures. 


\section{Meaningful Cultural Variation in the Instances of an Emotion}

Cultures afford certain patterns of emotional experience over others. Cultural influence is not strictly deterministic, and there is little reason to a priori assume withinculture homogeneity either across situations or among individuals. Yet, we expect to find systematic differences in the populations of emotional experiences, and consequently, experience types. To return to our prior example, we expect that, in situations like the bike removal, feelings of hostility and goal-blockage may be more common in the United States, where the pursuit of individual goals is in line with the central concern with independence, and self-assertion towards the caretaker (who is likely perceived as an obstacle in the scenario) may be a relatively more accepted means of getting there (e.g., Boiger, De Deyne, \& Mesquita, 2013; Markus \& Kitayama, 1991). In similar types of situations, we expect feelings of self-criticism and self-restraint to be more common in Japan, where individuals are particularly careful not to bother others (e.g., by placing a bike outside the designated area) in line with the central concern with interdependence (e.g., Heine, Takata, \& Lehman, 2000; Markus \& Kitayama, 1991); in this scenario, the caretaker may be perceived as enforcing a rule that is meant to make life smooth for everybody. Consequently, we expect that there are more people who feel anger like Heather in the US and more people who feel anger like Motoko in Japan, even though people who respond like Heather and people who respond like Motoko when they find their bike has been removed, exist in both countries. Culture, while not being deterministic, should account for systematic variance.

Importantly, there is cross-situational variance in emotional experience within cultures. This is illustrated by the reversal of Motoko's and Heather's respective anger experience in the example with the ranting student: In this situation, Motoko was the one who harbored hostile feelings towards her junior, while Heather felt self-critical. Relationships within the respective lab settings are differently constructed in the two cultures: Relationships 
in the Japanese lab follow a hierarchical structure and demand a certain level of respect from a junior toward a senior student (which does not allow for unrestrained ranting); in this scenario, hostility from a higher status to a lower status member may be acceptable in Japan (see also Park et al., 2013). In contrast, the U.S. lab takes a more collegial approach; a ranting student may still be considered a nuisance, but will likely be taken sufficiently serious to elicit doubts about the validity of one's points. In this case, interdependence means being respectful towards your seniors, and independence is associated with asserting your opinion, regardless of the type of relationship you are in. In the current study, we expected that multiple patterns of anger and shame experience are possible both across and within cultures, but that the distribution of these patterns differs systematically across cultures. Which instances are common and which are not should thus vary from culture to culture; those that are common can be expected to support central concerns of the respective cultural context (e.g., Mesquita, Boiger, \& De Leersnyder, 2016, 2017).

\section{The Current Study}

The aim of the current study was to establish if there is cultural variation in how people experience anger and shame. We focused on the contents of people's anger and shame experiences in concrete situations across three cultures: The United States, Japan, and (Dutchspeaking) Belgium. Previous research found differences in the intensity and frequency of anger and shame between these three cultural contexts (e.g., Boiger, De Deyne, et al., 2013; Boiger, Mesquita, Uchida, \& Barrett, 2013; Kitayama, Mesquita, \& Karasawa, 2006; Mu, Kitayama, Han, \& Gelfand, 2015), and suggested different context-specific appraisal patterns in the US and Japan (Boiger, Uchida, Norasakkunkit, \& Mesquita, 2016). We selected the U.S. and Japan because, even with more traditional empirical approaches, cultural differences in emotional experience have been established between these cultures. We added Belgium as a third culture to increase generalizability of our findings. Belgium is often grouped with the 
U.S. as a "Western," individualist culture. However, whereas American individualism stresses competition, relational mobility, and self-enhancement, Belgian individualism emphasizes compromise, maintenance of interpersonal relations, and self-restraint (Boiger, De Deyne, et al., 2013; Schwartz \& Ros, 1995).

We tested two hypotheses: First, we expected to find different types of anger and shame experiences, each characterized by a different population of anger or shame instances. The second prediction was that the distribution of these experience types would systematically differ across cultural contexts. To make sure that the situations, appraisals, and action tendencies included in the questionnaire were equally valid across cultures, we stayed as close as possible to people's everyday ecology of anger and shame experiences by bottomup sampling situations, appraisals, and action tendencies in each culture. ${ }^{2}$ We tested our predictions by identifying groups of participants with similar patterns of emotional experience (i.e., appraisals and action tendencies) across situations and then comparing the distribution of these inductively derived experience types across the three cultural contexts. Experience types were derived by applying CLASSI (Ceulemans \& Van Mechelen, 2008), a clustering technique that allowed us to group participants according to the appraisals and action tendencies that they experience across a range of situations. Participants that belong to the same experience type thus reported similar patterns of emotional experience, whereas participants that belong to different clusters appraise or feel motivated to react differently to at least some of the situations. Instead of assuming a homogenous set within each culture, the present approach allowed for experience types that are distributed across cultural contexts as well as types that are only found in one cultural context. Finally, we checked if the inductively derived experience types varied by variables other than participants' cultural background, such as their gender, socio-economic status, self-construal or Big Five personality dimensions. 


\section{Method}

\section{Participants}

We recruited 257 U.S. American students from Minnesota State University (Mankato), 271 Japanese students from Kyoto University and Tokyo Woman's Christian University, and 479 Belgian (Dutch-speaking) students from the University of Leuven and Lessius Hogeschool (Antwerp). The American students participated either as partial fulfillment of a course requirement or as a part of a larger study for which they received 10 USD $(27.6 \%$ of American participants). The Japanese participants at Kyoto University received 500 Yen book vouchers for their participation. The Japanese participants at Tokyo Woman's Christian University and the Belgian participants completed the questionnaire for partial fulfillment of a course requirement. After removing incomplete responses and participants who did not match the study criteria (i.e. students who were not born in their respective countries, had not moved there before the age of 13 , or had not spent there at least 10 years), our final sample consisted of 210 American $\left(72.4 \%\right.$ female, $\left.M_{\text {age }}=20.9, S a_{\text {ge }}=2.6\right)$, 264 Japanese $\left(56.1 \%\right.$ female, $M_{\text {age }}=$ 20.6, $\left.S D_{\text {age }}=1.7\right)$, and 454 Belgian $\left(81.1 \%\right.$ female, $\left.M_{\text {age }}=18.5, S D_{\text {age }}=1.2\right)$ students; the three samples differed significantly in age, $F(2,883)=195.5, p<.001$. The sample included in the analyses thus consisted of a total of 928 participants $\left(72.0 \%\right.$ female, $M_{\text {age }}=19.6, S D_{\text {age }}$ $=2.1$.

The U.S. American students identified as White/Caucasian-American (86.3\%), Asian/Asian-American (7.3\%), Black/African-American (2.4\%), Hispanic/Latino-American (1.5\%), ethnically mixed (1.5\%), Middle-Eastern (.5\%) and Native Pacific Islanders (.5\%). The Japanese students were all born in Japan and had no immigrant background. The Belgian students were White/Caucasian (94.5\%), Middle-Eastern (3.1\%), ethnically mixed (2.2\%), and Asian (.2\%). The full sample consisted of $65.6 \%$ White/European-American, $30.4 \%$ 
Asian/Asian-American, 1.6\% Middle-Eastern, 1.4\% ethnically mixed, .5\% Black/AfricanAmerican, .3\% Hispanic/Latino-American and .1\% Native Pacific Islanders participants.

\section{Preparation of Stimulus Material}

To capture instances of anger and shame, we measured appraisals and action tendencies of anger/shame across a range of standardized hypothetical anger/shame situations. Using a directed imagery task, we asked participants to imagine their experience of appraisals and action tendencies in response to each of these situations (for a similar method, see, e.g., Ceulemans, Kuppens, \& Van Mechelen, 2012). Within the limitations of this approach, we ensured that the stimulus material stayed as close as possible to people's everyday ecology of anger and shame experiences. We therefore conducted an extensive bottom-up sampling of situations, appraisals, and action tendencies in each culture (see Supplementary Material for a full description of the sampling procedure).

Based on previous research using a comparable directed imagery task of emotional experience (see Ceulemans et al., 2012) as well as our own pilot research, we deemed it feasible for participants to rate approximately 250 situation-appraisal/action tendency combinations. Because we had no a priori reasons to assume more variation in either the situational contexts or the components of anger and shame, we decided to give comparable weight to the number of situations and appraisals/action tendencies to be included in the current study. Consequently, we aimed to sample 15 situations (five per culture) and approximately 15 appraisals/action tendencies for anger and shame, respectively; a similar number of situations has been used successfully in previous research on the situated patterns of anger in one culture (Vansteelandt \& Van Mechelen, 2006).

Situation sampling. Short of studying the full population of anger and shame experiences, we selected a representative sample of situations. We obtained these situations by referencing previous interview and experience sampling research in the United States and 
Japan (Boiger, Mesquita, et al., 2013) and by replicating the respective studies in Belgium. While interviews yielded detailed descriptions of salient anger and shame antecedents, the experience sampling research generated daily accounts of anger and shame. Next, we ensured that the selection of situations was representative of the diversity of situations in each culture by plotting (a subset of) these situations in multidimensional spaces, one for anger and one for shame, and by retaining 15 situations (five per culture) that were distributed across these spaces. To do this, we scripted the situation descriptions from the interviews and experience sampling as short vignettes, took a random sample of 20 situations per culture (stratified by gender), and asked U.S., Japanese, and Belgian participants to sort them into as many categories as they saw fit. A multidimensional scaling (INDSCAL) of these card-sort data revealed that anger and shame situations could be distinguished based on two cross-culturally common dimensions and thus plotted in two-dimensional spaces. For anger, those dimensions were intentionality (purposeful versus inconsiderate actions of others) and interpersonal closeness (close others versus distant others); for shame, the dimensions were agency (situations caused by own vs. other actions) and the type of self-violations involved (public face vs. personal flaws). Tables A1 and A2 in Appendix A indicate for each situation on which side of the dimension it was situated. In our selection of situations, we made sure that the situations (1) were spread over the identified two-dimensional spaces such that some situations were blends of dimensions and others primarily defined by only one dimension and (2) that they had initially been reported to a comparable extent by males and females. The final selection of situations can be found in Appendix A.

Appraisal and action tendency sampling. We obtained ecologically valid and crossculturally representative appraisals and action tendencies by (1) creating exhaustive lists of appraisals and action tendencies of anger and shame from previously conducted interviews in each culture as well as from published (cross-cultural) research and by (2) identifying those 
appraisals/action tendencies that were most relevant to the experience of anger and shame in each culture. In a between-subjects design, we identified relevant items by asking U.S., Japanese, and Belgian participants to indicate for each appraisal/action tendency how strongly they thought it was associated either with anger or with shame. To yield a manageable selection of approximately 15 cross-culturally relevant appraisals/action tendencies per emotion, we selected the five appraisals/action tendencies that were by the participants perceived to be most relevant in each culture; we supplemented this set by the five items that varied most between cultures. After excluding items with high inter-correlations, we obtained a selection of eight anger appraisals, nine anger action tendencies, eight shame appraisals, and nine shame action tendencies that were included in the present study (see Appendix B).

\section{Instruments}

Situated Emotion Experience Questionnaire (SEEQ). The SEEQ consisted of a directed imagery task, in which participants indicated their imagined appraisals and action tendencies in response to each of the 15 previously selected situations. There were four versions of the SEEQ: Two anger questionnaires, one for female and one for male participants (SEEQ-A), and two shame questionnaires, one for female and one for male participants (SEEQ-S). The female and male versions differed only in terms of the protagonists' names in the situation vignettes and were otherwise identical in content; this measure was taken to ascertain sufficient identification with the protagonist. Female participants thus read situations about female protagonists and male participants read situations about male protagonists. The protagonists' names were the most popular names within the birth cohort of our targeted student samples (FOD Economie \& Economie, 2009; Meijiyasuda, 2009; Social Security Administration \& Administration, 2009); participants thus read vignettes about protagonists with popular names from their own culture, although two thirds of the situations were originally generated by respondents from the other two cultures. 
In all versions, participants read 15 situation vignettes (selection described above and in Supplementary Material; vignettes shown in Appendix A), and indicated for each situation how they would feel if this situation happened to them. An example of a shame vignette sampled from the U.S. is: "During a phone conversation, Ryan and his girlfriend Rebecca got into a fight. Things got out of hand, and Ryan started to cry and hung up. The next day during lunch break, Rebecca told other people at school that Ryan had started crying on the phone." Because all situations were interpersonal, we specified the protagonist with whom we wanted participants to identify themselves by including the protagonist's name in the instructions (e.g., "If I were in Ryan's situation, I would...). This instruction was followed by the list of the previously selected appraisals $(\mathrm{n}=8$, e.g., “...blame myself for the outcome of the situation) and action tendencies $(\mathrm{n}=9$, e.g., “...feel like withdrawing from the whole situation") (selection as described above and in Supplementary Material; appraisal/action tendency items shown in Appendix B); participants in the shame version rated shame appraisals/action tendencies and participants in the anger version anger appraisals/action tendencies. Again, because we wanted to make the transaction between the involved protagonists clear, we specified the targets of the appraisal and action tendency where necessary (e.g., “...... feel that the event decreased the others students' respect for me). Finally, participants reported the extent to which they would feel "angry" or "ashamed". 3 Participants indicated their responses to the appraisal, action tendency, and emotion items on a 7-point Likert scale ranging from 0 (not at all) to 6 (very much).

To keep the analysis of our data manageable in terms of computing power (nearly 1000 participants reporting their emotional experience in terms of 8 appraisals and 9 action tendencies across 15 situations), we performed clusterwise simultaneous component analyses (De Roover, Ceulemans, \& Timmerman, 2012) to summarize appraisals and action tendencies, conducting separate analyses for appraisals and action tendencies by emotion. 
Each participant's emotional instances, i.e., rating of the 15 situations in terms of their appraisals or action tendencies, were entered as a data block, excluding participants with missing data ( $<4 \%$ of all participants). We excluded two items ("perceiving the situation as unpleasant" and "perceiving the situation as serious") from the final analysis for both anger and shame because of cross-loadings on several components. Clusterwise simultaneous component analyses allowed us to establish if participants formed one cluster (that is, if there was a common component structure for all participants) or if they formed multiple clusters, for which the component structure differed. This would have been the case, if for example, the appraisals and action tendencies were differently understood in different cultures. All solutions were orthogonally rotated. Across emotions and for both appraisals and action tendencies, a one-cluster component structure across participants was justifiable, with solutions explaining on average $67.8 \%$ of the variance (see Appendix B for detailed solutions); a two-cluster solution would have explained on average only $2.4 \%$ more variance, which did not justify the increased complexity of the solution. This means that a crossculturally common component structure was appropriate. We used the component scores derived from these simultaneous component analyses as input for the main analyses. These component scores were person-centered with higher values indicating that a component was relatively more experienced in one situation compared to other situations by the respective participant; person-centering made the pattern of experiences across instances salient, while disregarding absolute levels of appraisals/action tendencies.

Individual-difference questionnaires. We included a number of individualdifference measures that had the potential of accounting for cultural differences in the distribution of emotional experience types beyond the cultural origin of the participants. To make it easier for respondents to answer the questionnaires, we unified the response format: All individual-difference scales were transformed to 7-point Likert scales. 
Big Five personality traits. The 45-item Big Five Inventory (John \& Srivastava, 1999) was used to measure the personality traits openness, conscientiousness, extraversion, agreeableness, and neuroticism; Big Five personality traits have been found related to interpersonal differences in anger and shame in North America, East Asia, and Belgium (Abe, 2004; Einstein \& Lanning, 1998; Kuppens, 2005; Spielberger \& Sydeman, 1994; Tong et al., 2006). Across samples and trait scales, Cronbach's alphas ranged from .63 (agreeableness in Japan) to .86 (extraversion in Belgium), and were on average $M=.80(S D=.05)$ in the U.S. sample, $M=.73(\mathrm{SD}=.07)$ in the Japanese sample, and $M=.80,(S D=.07)$ in the Belgian sample.

Self-construal. We measured participants' self-construal with the 30-item relational, individual, and collective self scale (Kashima \& Hardie, 2000); which self-aspect people emphasize differs across cultures and also affects the experience of emotions such as anger and shame (Kitayama et al., 2006; Markus \& Kitayama, 1991). Cronbach’s alphas ranged across samples and subscales from .66 (collective self in Japan) to .88 (relational self in Belgium $)$ and were on average $M=.81(S D=.03)$ in the U.S. sample, $M=.69(\mathrm{SD}=.03)$ in the Japanese sample, and $M=.85,(S D=.02)$ in the Belgian sample.

Regulatory focus. We also included a 18-item measure of regulatory focus (Lockwood, Jordan, \& Kunda, 2002); promotion and prevention focus have been shown to vary between cultures and affect emotional experience in culture-specific ways (Lee, Aaker, \& Gardner, 2000). Cronbach's alphas for promotion were .88 in the U.S. sample, .81 in the Japanese sample, and .82 in the Belgian sample; alphas for prevention were .79 in the U.S. sample, .63 in the Japanese sample, and .83 in the Belgian sample.

Emotion proneness and alexithymia. To account for any individual differences in emotion proneness we included the 10-item Spielberger Trait Anger Scale (Van der Ploeg, Defares, \& Spielberger, 1982) and the 3-item shame-proneness subscale from the Differential 
Emotions Scale (Izard, Libero, Putnam, \& Haynes, 1993). Finally, to capture individual differences in the ability to identify or describe one's feelings, we included the 20 -item Toronto Alexithymia Scale (Bagby, Parker, \& Taylor, 1994). Cronbach’s alphas ranged across samples and measures from .69 (shame in Japan) to .89 (anger in Japan) and were on average $M=.85(S D=.07)$ in the U.S. sample, $M=.76(\mathrm{SD}=.11)$ in the Japanese sample, and $M=.84,(S D=.08)$ in the Belgian sample.

\section{Procedure}

Half of the participants completed the shame questionnaire, half the anger questionnaire. The Japanese participants were invited to the lab to complete pen-and-paper questionnaires, the U.S. and Belgian participants completed online questionnaires. At the end of the questionnaire, all participants were debriefed about the goals of the study. The material was created in English and then translated to (1) Japanese by a professional translator who spent her childhood partly in Japan and partly in the United States and (2) to (Flemish) Dutch by native Dutch-speakers. Two of the authors, one of whom is a native Japanese-speaker and fluent in English and the other a native Dutch-speaker and fluent in English, checked all translations for accuracy.

\section{Analyses}

To test our first hypothesis, that is, that participants in our study represented different experience types that are marked by different populations of anger and shame instances, we used a recently developed classification model for individual differences in situated processes, called "CLASSI" (short for CLassification model for the Study of Sequential processes and Individual differences therein, Ceulemans \& Van Mechelen, 2008). Extending well-known Kmeans clustering, CLASSI has been specifically developed to identify groups of participants that have similar situated psychological responses. Thus, in the present context, groups of participants were formed that resemble one another in how they appraise and tend to act upon 
a range of situations. We refer to each group as an experience type because it subsumes participants with similar instances of emotional experience. To the extent that each type subsumes a different population of anger or shame instances, variation in experience types also speaks to variation in the experience of anger and shame. For a more elaborate description of the CLASSI model, we refer to Ceulemans and Van Mechelen (2008) and Ceulemans, Kuppens, and Van Mechelen (2012). ${ }^{4}$

To test our second hypothesis, that there are cultural differences in the distribution of these anger and shame types, we compared the distribution of the experience types over participants from different cultural background using chi-square tests. Next, to check if individual background variables and dispositions other than the participant's cultural origin was differently distributed over experience types (e.g., that participants of one experience type were more likely to be female, high SES, or extraverted), we conducted multinomial logistic regressions in which we predicted experience types by participant's cultural origin as well as a range of potentially relevant variables such as participants' self-construal, SES, gender, personality, regulatory focus, anger/shame proneness and alexithymia.

\section{Results}

\section{Different Types of Anger and Shame Experience}

To test our first hypothesis that there are different types of anger and shame experiences across participants, we followed Ceulemans and Van Mechelen's (2008) suggestion to analyze the data with varying numbers of types, and to use a scree-test-based model selection method (Ceulemans \& Kiers, 2006). We conducted all analyses with one to five experience types; for each analysis, we used ten random starts. For anger, the scree-test pointed to two types of experiencing anger. For shame, the procedure pointed to either two or three experience types. Because we expected emotional experience to differ between the three 
cultural groups, we first explored the theoretically expected (i.e. meaningful) three-type solutions for both emotions, and additionally investigated the two-type solution for anger.

The three induced anger experience types consisted of 143 (33.9\%), 130 (30.8\%), and $149(35.3 \%)$ participants, respectively; the solution explained $26 \%$ of the variance in the data. The two-type solution for anger consisted of 147 (34.8\%) and 275 (65.2\%) participants, with type 2 of the two-type solution almost completely subsuming type 1 and type 3 of the threetype solution (94.2\%). A two-type solution explained $25 \%$ of the variance in the data, which was hardly less than the solution with three experience types. The three induced shame experience types consisted of 170 (36.9\%), 113 (24.5\%), and 178 (38.6\%) participants, respectively; the solution explained $31 \%$ of the variance in the data.

\section{Cultural Variation in Anger and Shame Experience}

Anger. We first tested our prediction that the distribution of anger experience types varies between participants from the U.S., Japan, and Belgium. Table 1 shows the distribution of the anger experience types across the three cultural groups. In line with our general hypothesis, we found that the distribution of the anger experience types varied significantly across cultural contexts, $\chi^{2}(4)=260.54, p<.001$, Cramer's $V=.56, p<.001$. Nonetheless, each experience type was reported in each culture, if only by a few participants. A culturally "dominant" pattern of anger instances was most discernible for the Japanese participants: A majority $(90.1 \%)$ of the Japanese participants reported the pattern captured by type 2 . The findings were less clear for the U.S. and Belgian participants, with approximately equal numbers of participants falling into either type 1 or 2 . We conducted post-hoc analyses to check for the possibility that we could not identify a dominant anger experience type among U.S. participants because of the ethnic diversity in this sample; however, there were no ethnic differences in the distribution of experience types within the U.S. sample, $\chi^{2}(8)=7.57, p=$ .48. 
Because type 1 and type 3 were similarly distributed among U.S. and Belgian participants, and based on the results from the scree plot procedure, we also explored the cross-cultural distribution of a two-type solution (see Table 1). The distribution of these two anger experience types differed significantly across cultures, $\chi^{2}(2)=264.45$, Cramer's $V=$ $.79, p<.001$, with most Japanese participants (96.4\%) falling into one type and most U.S. (73.0\%) and Belgian (93.8\%) participants falling into the other type (see cells printed in bold in Table 1). Inferring from this commonality in the dominant anger experience type, it seems that the population of anger instances in the U.S. was not substantially different from the population in Belgium. Based on this allocation of culturally dominant experience types, we were able to distinguish between Japanese, and "Western" (i.e., U.S. and Belgian) participants - solely on the basis of their appraisals and action tendencies across hypothetical anger situations - with an accuracy of $72.3 \%$ (proportion of "correct" classifications).

Next, we explored differences in the content of these anger experience types. Without reducing experience types to simple averages (or essences), cultural differences are not easily illustrated. Each type refers to a different pattern of anger instances (in response to 15 situations), each consisting of a combination of appraisals and action tendency components. To visualize differences in the patterns we highlighted cells with large differences between anger experience type 1 and 2 (see Table C1, Appendix C). To do this, we calculated, for each combination of situation and appraisal/action tendency component, the squared difference between type 1 and 2; we then highlighted cells for which the squared difference was above the mean. There are two ways in which differences between the anger experience types can be discussed: per situation or per appraisal/action tendency component. Per situation, the sums of squared differences in Table $\mathrm{C} 1$ reveal that some situations are associated with different patterns of emotional experience in the Japanese and U.S./Belgian type (e.g., "stairs collision", "slow at ATM"), whereas other situations come with similar patterns (e.g., 
"belated friend" or "shared secrets"). It is hard to pinpoint what it is about those situations that afforded more variation in emotional experience compared to those that did not.

Per appraisal/action tendency, it is equally evident that certain appraisals/action tendencies played a larger role in creating variation in anger instances between types, as indicated by the column sums of squared differences in Table C1: For example, the "Japanese" and "U.S./Belgian" anger experience type differed substantially in terms of the situations in which participants thought they would blame the other person (appraisal of "other-blame") or feel paralyzed/overpowered by their anger (action tendency of "preoccupation"). In comparison, participants of both types agreed in terms of when they thought it was most appropriate to do nothing (action tendency of "non-action").

To illustrate differences in the population of anger instances between the two types, Figure 2 shows to what extent the appraisal of other-blame and the action tendendency of preoccupation (see Appendix B for details on their component structure) make up the anger experiences of type 1 and 2 for four exemplary situations. As outlined above, the situations in the present study had been sampled from a two-dimensional space, found to describe angereliciting situations across cultures; the dimensions were intentionality (purposely harmful vs. merely inconsiderate interaction partners) and interpersonal closeness (close vs distant interaction partners). For illustrative purposes, we referenced the four quadrants of the twodimensional space defined by these dimensions, and selected from each quadrant the situation that yielded the most differences in responding between the types (bold situations in Table C1, Appendix C). For ease of interpretation, the situations in the Figure are labeled according to the respective quadrant from which they were sampled: Inconsiderate close others, purposeful close others, inconsiderate distant others, purposeful distant others.

During situations in which people were purposefully mean, anger experiences of both types were marked by more other-blame than during situations in which others were merely 
inconsiderate. However, anger experiences of type 1 (the most common type in Japan) were characterized by more other-blame when distant others were involved than anger experiences of type 2 (the most common type in the U.S. / Belgium); the reverse pattern was found for situations with close others. In these four exemplary situations, it appears that Japanese are more protective of their relationships with close others than their relationships with distant others, while Americans and Belgians may feel entitled to good treatment by close others, and at any rate hold those close others more accountable for their actions. The pattern for preoccupation mirrored the pattern for other-blame: Participants with type 1 anger experiences (a majority of Japanese) were more preoccupied with their feelings (that is, feel paralyzed or overpowered by their anger) in situations with close others than were participants with type 2 anger experiences (a larger group of Americans and Belgians; the latter were relatively more preoccupied with their feelings in situations with distant others. Preoccupation may be prevalent in situations marked by other-blame because blaming another person involves pondering on the motives of that person and considering an appropriate course of action.

Shame. Table 2 shows how the empirically induced shame experience types are distributed over the three cultural groups. In support of our hypothesis, we found that the distribution of the shame experience types varied significantly over cultures, $\chi^{2}(4)=437.89, p$ $<.001$, Cramer's $V=.69, p<.001$, suggesting that the populations of shame experiences differ between the cultures. A culturally dominant type stood out in each culture, suggesting that the population of shame instances varied systematically between cultures. Again, the Japanese participants displayed the most distinct way of experiencing shame: The majority of Japanese participants (91.2\%) fell into type 2. Furthermore, the majority of U.S. (77.1\%) and Belgian (64.4\%) participants also reported distinct pattern as captured by types 1 and 3, respectively. The culturally dominant shame experience types are shown in bold in Table 2; it 
was possible to predict a participant's cultural origin with $74.0 \%$ accuracy based on these culturally dominant experience types.

We then explored differences in the content of the three shame experience types (see Table C2, Appendix C). Analogous to anger, we visualized differences in the patterns by highlighting those cells for which the squared difference was above the mean. Because we had identified three types, we calculated squared differences for each combination of situation and appraisal/action tendency between the smallest and largest value across the three types. Again, we approached the table in two ways - per situation and per appraisal/action tendency component. An inspection of the table revealed that certain shame situations were associated with different patterns of appraisals and action tendencies across the U.S., Japanese and Belgian types (e.g., "phone mum", "undress at spa"), whereas other situations afforded comparable experience patterns (e.g., "crying on phone" or "misunderstood lyrics"). Again, it was difficult to pinpoint what distinguished those situations that came with different patterns from those situations that did not.

By appraisal/action tendency component, shame experience types differed from each other primarily in terms of appraisals of shame situations; less variation between types was found in the action tendencies. The main differences between types were in terms of when people tried to play down the relevance of a situation (appraisal of "relativizing") or when they focused on others" perception of them (appraisal of "other-esteem"). To illustrate the differences in experience types, we again selected situations from the four quadrants created by the two dimensions that we had identified in our preliminary research. The two dimensions were agency (situations caused by own vs. others' actions) and the type of self-violations involved (public face vs. personal flaws). These dimensions parallel the dominant cultural values and ideals in the U.S. and Japan: Being free from external influence (other-agency) and not feeling bad about oneself (personal flaws) mirror the U.S. concern with independence and 
high self-esteem; being in control of one's actions (self-agency) and not looking bad in public (face loss) correspond to the Japanese concern for adjusting to others and interdependence (see Boiger, Mesquita, et al., 2013). The profile for relativizing and other-esteem appraisals across these four exemplary situations is shown in Figure 3 (situations named according to the respective quadrant from which they were sampled).

Because "relativizing" implies not making too much out of a situation, it is informative to look at those situations in which relativizing was relatively less prominent (and the situation thus likely touching on important values). In a situation where others caused face loss, type 2 shame, which was the dominant type of experiencing shame in Japan, was characterized by the least intense appraisal of relativizing. In other words, and fitting Japanese cultural concerns, situations in which others make you look bad is not something to be taken lightly. In comparison, the same situation was more readily relativized (that is, played a less central role) in type 1 shame, which was the most common type in the United States. The pattern reverses for situations in which others reveal personal flaws: These situations came with an intense appraisal of relativizing (i.e., of not taking the situation seriously) for the dominant Japanese type, but much less so for the dominant U.S. type, for whom these situations touch on central cultural concerns. The opposite pattern emerged for situations in which personal flaws are revealed: While these situations were played down in type 2 (the "Japanese" type), they were nothing to be taken lightly for the other two types. Type 3 shame, the "Belgian" type, displayed a pattern of aligning with the dominant U.S. type for the two situations in which personal flaws were revealed and of falling in-between the "U.S" and "Japanese" type for the two situations involving face loss. The pattern for other-esteem looked comparatively more similar across types, with all shame experience types being characterized by the highest levels of other-esteem in instances in which others revealed their personal flaws. 


\section{Cultural Variation or Individual Differences in Emotional Experience?}

We checked whether the anger and shame experience types that we identified varied across participants by variables other than participants' cultural background. We therefore conducted multinomial regressions, in which we assessed if the participants who belong to an experience type differed not only in terms of their cultural origin, but also by their sociodemographic background, Big Five personality traits, self-construal, regulatory focus, anger/shame proneness and tendency for alexithymia. The included individual-difference variables have been found to vary across cultures and to influence individual's emotional experience; sociodemographic background and self-construal have been used to capture people's cultural affiliations in past research (see Oyserman, Coon, \& Kemmelmeier, 2002; Snibbe \& Markus, 2005). Table 3 shows the variables that significantly predicted a participant's experience type. We used the three -type solutions for both anger and shame, because it made the analyses comparable across emotions; however, running the analysis with the two-type solution for anger yielded the same pattern of results.

The participants' cultural background was by far the strongest predictor of their anger or shame type, even when controlling for all other variables. However, there were other, much weaker, predictors of a participant's experience type. Gender was a predictor, with anger and shame types 1 and 3 being more common among female participants. Socio-economic status predicted anger type, with anger type 3 being more common among participants of higher socioeconomic status than type 2 . Agreeableness predicted shame type, with shame type 1 being more common among participants high in agreeableness than types 2 and 3; selfconcept was another significant predictor, with shame types 1 and 3 being more common among participants with a more pronounced individual self-concept than type 2 . Given that culture was a far better predictor of anger and shame types than were the other demographic 
and personality descriptor, the variation in anger and shame experience is best described as cultural variation.

\section{Discussion}

What do we mean when we ask if emotions like anger and shame vary across cultures? The current study took a novel approach to this question. Rather than assuming that individuals always experience anger or shame in the same way, our starting point was that variance is at the heart of emotional experience. The experience of an emotion like anger or shame may vary from one instance to another, even for the same person or within the same culture. This means that cross-cultural comparisons of emotional experience are comparisons of the populations of emotion instances (Barrett, 2006, 2017a, 2017b). The question whether emotions differ would be answered positively if the cultural distributions of emotion instances differ, and negatively if, and to the extent, they overlap. We started from experience types, that is, groups of people who differ in the instances of anger and shame that they experience; in our study, emotional experience was captured by appraisal and action tendencies. Taking this approach, we showed that populations of anger and shame instances respectively differed between the United States, Japan, and Belgium.

We started out with an extensive set of preliminary studies to sample ecologically valid and culturally representative situations, appraisals, and action tendencies of anger and shame. Using cross-culturally meaningful appraisals and action tendencies, U.S. American, Japanese, and Belgian students then indicated how they would appraise each of a set of crossculturally representative situations, and what they would feel like doing about it. To simplify our analyses, we reduced appraisals and action tendencies into appraisal components and action tendency components. A cross-culturally common component structure was justifiable, underlining that the items were understood in similar ways across cultures. This means that, at this lower level, the structure of emotional meaning was cross-culturally similar; a finding 
that is consistent with the assumptions of appraisal theories that there are universal building blocks of (primitive) meaning (e.g., Ellsworth \& Scherer, 2003). In this research, we found these building blocks to be other-blame, self-blame and goal-blockage (anger appraisals); aggression, preoccupation and non-action (anger action tendencies); other-esteem, relativizing, and self-esteem (shame appraisals); and avoidance, composure, patience and apologizing (shame action tendencies).

We first established different experience types for both anger and shame; that is, different populations of anger and shame instances (hypothesis 1). These instances were defined in terms of their components of appraisal and action tendencies across 15 hypothetical situations. We inferred experience types, using the CLASSI-model, which ensures that different anger and shame types are maximally distinct from each other. We established two anger and three types. Again, it is interesting to note that the same anger and the same shame types were found in all three cultural groups. That is, in each culture were at least a few participants that experienced each anger/shame type, despite our method allowing for culturally specific types.

We then checked if the distribution of these experience types differed systematically by participants' cultural backgrounds (hypothesis 2). As predicted, there were systematic cultural differences in the distribution of both anger and shame experience types. For anger, we identified two experience types that varied systematically between the Japanese and "Western" (i.e., U.S. and Belgian) participants. We found one culturally dominant Japanese type that was reported by $96.4 \%$ of all Japanese participants; the other experience type was reported by the majority of Americans and Belgians. When it comes to anger, the majority of Americans and Belgians in our sample thus drew on a shared a population of anger instances. For shame, we identified three experience types that varied systematically across cultures: In each cultural context, one shame experience type stood out as a dominant type. The cultural 
differences in distribution were so pronounced that it was possible to infer a participant's cultural background with $74.0 \%$ accuracy by knowing their experience type or, in other words, by knowing how they responded emotionally to 15 hypothetical situations. The majority of participants from each cultural group thus clearly reported a different population of shame instances. Whereas the building blocks of emotional experience were found to be cross-culturally similar at the level of appraisal and action tendencies as well as at the level of experience types, the actual populations of emotional instances differed greatly. When answering the question of cultural differences in the ways people experience anger or shame, our findings indicate substantial and systematic differences.

Finally, we found that the established anger and shame types varied primarily by participants' cultural backgrounds, and that individual-difference or demographic factors were for the most part evenly distributed over types. This finding is consistent with the idea of culture as a dynamic system in which external realities - e.g., daily practices, material artifacts, social institutions and structures — shape human experience (Kitayama, 2002).

\section{What Are the Differences in Anger and Shame Experience?}

We had not made specific predictions about the content of the anger and shame experience types given the complexity and inductive nature of our research. The classification model we used to identify participants with similar patterns of emotional experience efficiently assigned participants to types; yet, describing the nature of these experience types remained very complex - precisely because they could not be reduced to a simple essence. Each experience type consisted of matrixes of 6 anger (7 shame) appraisal and action tendency components by 15 situations (see Appendix C). This is a substantial reduction in complexity from the original data (495 instead of nearly 250,000 data points), yet it remains challenging to distill one clear message about what makes up for the type. 
To illustrate the differences in experience between different types, we zoomed in on appraisals and action tendencies that distinguished most between them. For anger these were the appraisal fo other-blame and the action tendency of preoccupation. For shame these were the appraisals of relativizing and otheresteem. We explored these appraisals and action tendencies for exemplary situations. Situations were selected to cover the two-dimensional space that cross-culturally defined the anger or shame situations. We compared different anger and shame types with respect to the selected appraisal and action tendencies. In the following, we will dicuss only the findings for the anger appraisal of other-blame because the pattern for preoccupation was rather similar; we also discuss only the findings for the shame appraisal of relativizing because the differences were much less pronounced for other-esteem.

For the anger appraisal of other-blame we found that the Japanese participants (who primarily experience anger type 1) blamed distant others who were purposefully rude (e.g., strangers who holler at them on a narrow stairway), the U.S. and Belgian participants (who primarily experienced anger type 2) primarily blamed close others who failed to meet relational norms (e.g., a boyfriend who was not available after bad news from the doctor). What made these anger types different parallels central concerns in each cultures: While Japanese are primarily concerned with protecting their close relationships (and thus refrain from other-blame in these instances), Americans and Western European are more concerns with protecting their autonomy (and this concern plays a more central role in close relationships where relational norms ensure good treatment while allowing for autonomy) (Boiger et al., 2016). CLASSI analyses could be a starting point for studying the content of emotional experiences in more detail, and future research may want to look more closely at what it is about cultures that produces similarities and differences in situated patterns of emotional experience. 
For the shame appraisal of relativizing, we also found that in each culture, people felt like relativizing those situations that were not structured around central concerns in their culture (while caring more for those that matter most): In Japan, the dominant response was not to worry too much about situations in which personal flaws were revealed, while situations in which one looked bad in public was not something to relativize or take lightly. This mirrors the Japanese concern with face (Cocroft \& Ting-Toomey, 1994; Lebra, 1976) as well as our previous research finding that Japanese perceive shame to be primarily about looking bad in public (Boiger, Mesquita, et al., 2013). In contrast, the dominant response in the United States was one of relativizing the importance of public exposure, but finding it hard to relativize when others point out personal flaws. Again, this matches the prevalent U.S. concern with feeling good about oneself and maintaining autonomy from (the opinions of) others (Heine, Lehman, Markus, \& Kitayama, 1999; Kim, Cohen, \& Au, 2010). It is interesting to note that the "Belgian" type aligned with the "U.S." type in not taking the revelation of personal flaws lightly, but fell in between the "U.S" and "Japanese" type when it comes to looking bad in public; an analysis by situation revealed a more nuanced profile here and may explain why Western European emotional responses sometimes match Japanese responses (e.g., Boiger, 2013) and at other times showed a pattern that fell in-between Japan and the U.S. (e.g., Kitayama et al., 2009).

Our findings show that anger and shame experiences differ from instance to instance, and that, in each culture, a majority of the people share a specific way of responding emotionally to the same set of situations. In daily life, these differences become even more pronounced as people in different cultures do not experience the same set of situations - that is, not only does their experience within certain situations differ, the ecology of emotional situations itself differs. For example, we have found in previous research that people tend to encounter more situations that elicit emotional experiences that are conducive to the 
relationship ideals in their culture (Boiger, De Deyne, et al., 2013; Boiger, Güngör, Karasawa, \& Mesquita, 2014; Boiger, Mesquita, et al., 2013). These different ecologies will lead to an even larger variety of instances that people in different cultures actually subsume under an emotional category such as anger or shame than we could capture with a set of standardized hypothetical situations in the current study.

\section{The Role of Heterogeneity Within Cultures}

There is coherence in emotional experience within cultural contexts (with up to $96 \%$ of a cultural group displaying a similar emotional pattern); yet, there is also evidence for heterogeneity within cultures. Our research participants were sampled from relatively homogenous groups: We used student samples recruited from no more than two different universities per cultural setting. Despite this homogeneity in samples, participants within one culture did not converge with respect to their patterns of emotional experience. There are several explanations. First, people are not executing clearly defined cultural programs

(“culture writ small”, Mendoza-Denton \& Mischel, 2007), but actively enact culture. Through their ongoing engagement and collaboration with physical, symbolic and social environments, they "do" culture in each moment. To the extent that these environments are never identical for two individuals, people may vary in their exact enactment of cultural patterns, leading to heterogeneity within cultures. Second, people differ in the extent to which they are compelled to internalize and consequently enact cultural norms. For example, certain individuals may be more sensitive to social rewards and consequently more willing to align their enactment of culture with social norms (see Kitayama et al., 2014). It is imaginable that these rewardsensitive individuals may have been over-represented in our student samples, allowing us to find dominant patterns in each culture.

Why Heterogeneity Matters: Connecting Research with Practice 
Approaching people's emotional experience (and cultural differences therein) in ways that reflect the heterogeneity of human experience matters not only for creating sound research but also, and especially, for how research can influence practice and public discourse. The idea that people's context-specific instances of certain emotions can take on different forms in different cultures may seem trivial at first sight, yet it has important implications: For researchers, it seriously puts in question the use of single-item emotional intensity measures ("how angry did you feel"?) on which most emotion researchers - the authors of the present study included - have heavily, if not exclusively, relied. While a fullscale assessment of multiple components across a range of relevant situations may not always be feasible, (cross-cultural) research would benefit from including one or two theoretically relevant contextual dimensions and supplementing the predominant intensity measures of emotion labels with other channels of emotional information (e.g., appraisals, action tendencies, physiology, expression...).

Research using single-item measures may ultimately also encourage essentialist thinking in practitioners. If research tells us little about variation in, e.g., the content of shame experiences that people encounter and how these experiences may differ across cultures, there is little that can be taught to students and future practitioners about heterogeneity in shame. This may have implications, e.g., for the mindset that therapists bring to their practice. Think, for example, of a therapist working with an immigrant client who reports "unexpected" emotions in therapy (e.g., shame in response to a seemingly harmless mistake). A therapist starting from an essentialist stance will likely rely on his preconceptions of shame and may unwillingly steer the conversation in the direction of his presumptions (e.g., what made the client feel flawed or inadequate). In contrast, a therapist who takes heterogeneity seriously will actively explore the appraisals and feelings that mattered during the situation (and may discover, e.g., that the client primarily worried about making themselves look bad in the eyes 
of others, see also Boiger, Mesquita, et al., 2013; Gausel, 2014). We believe that our multicultural worlds and societies will be better served by research and practice that start from the idea that understanding heterogeneity and variation is a worthwhile endeavor.

\section{Limitations and Future Directions}

There are a number of limitations to the present research. First, this study relied on participants' imagined responses to situational vignettes, which may differ from experience in daily life. This kind of data was required for the analyses we conducted: Situations needed to be the same across participants to model variation in participants' context-specific responses; if the situations had not been comparable across participants, it would have been impossible to distinguish person variation from situation variation. Although directed imagery tasks such as this have been successfully used in comparable personality research (Kuppens, Van Mechelen, \& Rijmen, 2008), emotional experience as captured by imagined responses to vignettes may be more influenced by social desirably than online experience in daily life.

Furthermore, some of the cultural variation we found may have been driven by lessthan-perfect translations of the situations or appraisals/action tendencies. However, the fact that we relied on detailed (multi-word) descriptions of situations and appraisals/action tendencies makes it less likely that translations modified meanings-compared to research that relies on translations of single emotion words, which is the common approach in much cross-cultural emotion research. Even if the translations of specific items introduced some bias across cultures, we used component scores that summarized information across appraisals and action tendencies and therefore reduced the impact of the wording of any one item.

Finally, the current study included large samples of participants, but only incorporated a limited range of situations. It is conceivable that emotional experiences vary across cultures not only because people respond differently to situations, but also because certain situations 
afford different, culture-specific emotional patterns (Boiger, Mesquita, et al., 2013; Kitayama, Markus, Matsumoto, \& Norasakkunkit, 1997). Future research may want to include larger samples of situations, possibly at the expense of the number of appraisals/action tendencies (or by first establishing cross-cultural sound factors underlying of appraisals / action tendencies).

\section{Conclusion}

In the current study, we started from the idea that average comparisons of emotional intensities can only tell so much about what makes people's emotional lives different across cultures. In daily life, the differences that stand out are much more fine-grained and contextdependent. Consequently, what strikes us as different when we travel to faraway places is that people often tend to deal with situations in unexpected ways. For example, if Heather were to visit Motoko, she may be surprised to find Motoko deal calmly with her frustration about a towed bike while talking at length about her junior's inappropriate behavior-both behaviors hint towards anger, but do so in different, culture-specific ways. The appraisals and action tendencies that make up the respective instances of anger constitute starting points for exploration and, possibly, cultural understanding: Heather may leave Japan having learned about hierarchies and face maintenance (which made the ranting student's behavior inappropriate and inacceptable), as well as about the importance of accepting rules for keeping social order and harmony (which made a misplaced bike potentially troublesome to others and its removal frustrating but ultimately one's own fault). We propose that the same holds for researchers: The most promising route forward toward understanding cultural variation in people's emotional experience will be to study the respective populations of emotion instances across cultures. Doing so will allow research to move beyond the essentialism that has plagued psychological thinking for much of the last century and to better understand the heterogeneity and unfixed nature of human experience. 


\section{References}

Abe, J. A. (2004). Shame, guilt, and personality judgment. Journal of Research in Personality, 38, 85-104.

Bagby, R. M., Parker, J. D. A., \& Taylor, G. J. (1994). The twenty-item Toronto Alexithymia Scale-I: Item selection and cross-validation of the factor structure. Journal of Psychosomatic Research, 38, 23-32.

Barrett, L. F. (2006). Solving the emotion paradox: Categorization and the experience of emotion. Personality and Social Psychology Review, 10, 20-46.

Barrett, L. F. (2013). Psychological construction: The Darwinian approach to the science of emotion. Emotion Review, 5, 379-389.

Barrett, L. F. (2017a). Categories and their role in the science of emotion. Psychological Inquiry, 28, 20-26.

Barrett, L. F. (2017b). How emotions are made: The secret life of the brain. Boston, MA: Houghton Mifflin.

Barrett, L. F., Mesquita, B., Ochsner, K. N., \& Gross, J. J. (2007). The experience of emotion. Annual Review of Psychology, 58, 373-403.

Barrett, L. F., Mesquita, B., \& Smith, E. R. (2010). The context principle. In B. Mesquita, L. F. Barrett, \& E. R. Smith (Eds.), The mind in context (pp. 1-22). New York: Guilford Press.

Boiger, M. (2013). Emotion in context: Constructions of anger and shame in four cultures. University of Leuven.

Boiger, M., De Deyne, S., \& Mesquita, B. (2013). Emotions in "the world": Cultural practices, products, and meanings of anger and shame in two individualist cultures. Frontiers in Psychology, 4, 1-14.

Boiger, M., Güngör, D., Karasawa, M., \& Mesquita, B. (2014). Defending honour, keeping 
face: Interpersonal affordances of anger and shame in Turkey and Japan. Cognition \& Emotion, 28, 1255-1269.

Boiger, M., \& Mesquita, B. (2012). The construction of emotion in interactions, relationships, and cultures. Emotion Review, 4, 221-229.

Boiger, M., Mesquita, B., Tsai, A. Y. A. Y., \& Markus, H. R. (2012). Influencing and adjusting in daily emotional situations: A comparison of European and Asian American action styles. Cognition \& Emotion, 26, 332-340.

Boiger, M., Mesquita, B., Uchida, Y., \& Barrett, L. F. (2013). Condoned or condemned: The situational affordance of anger and shame in the United States and Japan. Personality and Social Psychology Bulletin, 39, 540-553.

Boiger, M., Uchida, Y., Norasakkunkit, V., \& Mesquita, B. (2016). Protecting autonomy, protecting relatedness: Appraisal patterns of daily anger and shame in the United States and Japan. Japanese Psychological Research, 58, 28-41.

Ceulemans, E., \& Kiers, H. A. L. (2006). Selecting among three-mode principal component models of different types and complexities: A numerical convex hull based method. The British Journal of Mathematical and Statistical Psychology, 59, 133-150.

Ceulemans, E., Kuppens, P., \& Van Mechelen, I. (2012). Capturing the structure of distinct types of individual differences in the situation-specific experience of emotions: The case of anger. European Journal of Personality, 26, 484-495.

Ceulemans, E., \& Van Mechelen, I. (2008). CLASSI: A classification model for the study of sequential processes and individual differences therein. Psychometrika, 73, 107-124.

Chentsova-Dutton, Y. E., \& Tsai, J. L. (2010). Self-focused attention and emotional reactivity: The role of culture. Journal of Personality and Social Psychology, 98, 507519.

Cocroft, B.-A. K., \& Ting-Toomey, S. (1994). Facework in Japan and the United States. 
International Journal of Intercultural Relations, 18, 469-506.

De Roover, K., Ceulemans, E., \& Timmerman, M. E. (2012). How to perform multiblock component analysis in practice. Behavior Research Methods, 44, 41-56.

Eid, M., \& Diener, E. (2001). Norms for experiencing emotions in different cultures: Interand intranational differences. Journal of Personality and Social Psychology, 81, 169202.

Einstein, D., \& Lanning, K. (1998). Shame, guilt, ego development, and the five-factor model of personality. Journal of Personality, 66, 555-582.

Ellsworth, P. C. (2013). Appraisal theory: Old and new questions. Emotion Review, 5, 125131.

Ellsworth, P. C., \& Scherer, K. R. (2003). Appraisal processes in emotion. In R. J. Davidson, K. R. Scherer, \& H. H. Goldsmith (Eds.), Handbook of affective sciences (pp. 572-595). Oxford, UK: Oxford University Press.

FOD Economie, \& Economie, F. O. D. (2009). Meisjes- en jongensnamen 1979-1989.

Frijda, N. H. (2007). The laws of emotion. Hillsdale, NJ: Lawrence Erlbaum Associates.

Frijda, N. H., Kuipers, P., \& ter Schure, E. (1989). Relations among emotion, appraisal, and emotional action readiness. Journal of Personality and Social Psychology, 57, 212-228.

Gausel, N. (2014). What does "I feel ashamed" mean? Avoiding the pitfall of definition by understanding subjective emotion language. In K. G. Lockhart (Ed.), Psychology of shame: New research (pp. 157-166). Hauppauge, NY: Nova Publishers.

Heine, S. J., Lehman, D. R., Markus, H. R., \& Kitayama, S. (1999). Is there a universal need for positive self-regard? Psychological Review, 106, 766-794.

Heine, S. J., Takata, T., \& Lehman, D. R. (2000). Beyond self-presentation: Evidence for selfcriticism among Japanese. Personality and Social Psychology Bulletin, 26, 71-78.

Imada, T., \& Ellsworth, P. C. (2011). Proud Americans and lucky Japanese: Cultural 
differences in appraisal and corresponding emotion. Emotion, 11, 329-345.

Izard, C. E. E., Libero, D. Z. Z., Putnam, P., \& Haynes, O. M. M. (1993). Stability of emotion experiences and their relations to traits of personality. Journal of Personality and Social Psychology, 64, 847-860.

John, O. P., \& Srivastava, S. (1999). The Big Five trait taxonomy: History, measurement, and theoretical perspectives. In L. A. Pervin \& O. P. John (Eds.), Handbook of personality: Theory and research (2nd ed., pp. 102-138). New York, NY: Guilford Press.

Kashima, E. S., \& Hardie, E. (2000). The development and validation of the Relational, Individual, and Collective self-aspects (RIC) Scale. Asian Journal of Social Psycholog, $3,19-48$.

Kim, Y.-H., Cohen, D., \& Au, W.-T. (2010). The jury and abjury of my peers: the self in face and dignity cultures. Journal of Personality and Social Psychology, 98, 904-16.

Kitayama, S. (2002). Culture and basic psychological processes - Toward a system view of culture: Comment on Oyserman et al. (2002). Psychological Bulletin, 128, 89-96.

Kitayama, S., King, A., Yoon, C., Tompson, S., Huff, S., \& Liberzon, I. (2014). The dopamine D4 receptor gene (DRD4) moderates cultural difference in independent versus interdependent social orientation. Psychological Science, 25, 1169-1177.

Kitayama, S., Markus, H. R., Matsumoto, H., \& Norasakkunkit, V. (1997). Individual and collective processes in the construction of the self: Self-enhancement in the United States and self-criticism in Japan. Journal of Personality and Social Psychology, 72, 12451267.

Kitayama, S., Mesquita, B., \& Karasawa, M. (2006). Cultural affordances and emotional experience: Socially engaging and disengaging emotions in Japan and the United States. Journal of Personality and Social Psychology, 91, 890-903.

Kitayama, S., Park, H., Sevincer, A. T., Karasawa, M., Uskul, A. K. A. K., Sevincer, H. T., ... 
Uskul, A. K. A. K. (2009). A cultural task analysis of implicit independence: comparing North America, Western Europe, and East Asia. Journal of Personality and Social Psychology, 97, 236-255.

Kuppens, P. (2005). Interpersonal determinants of trait anger: low agreeableness, perceived low social esteem, and the amplifying role of the importance attached to social relationships. Personality and Individual Differences, 38, 13-23.

Kuppens, P., Van Mechelen, I., \& Rijmen, F. (2008). Toward disentangling sources of individual differences in appraisal and anger. Journal of Personality, 76, 969-1000.

Kuppens, P., Van Mechelen, I., Smits, D. J. M., De Boeck, P., \& Ceulemans, E. (2007). Individual differences in patterns of appraisal and anger experience. Cognition and Emotion, 21, 689-713.

Lebra, T. S. (1976). Japanese patterns of behavior. Honolulu, HI: University of Hawaii Press. Lee, A. Y., Aaker, J. L., \& Gardner, W. L. (2000). The pleasures and pains of distinct selfconstruals: The role of interdependence in regulatory focus. Journal of Personality and Social Psychology, 78, 1122-1134.

Lockwood, P., Jordan, C. H., \& Kunda, Z. (2002). Motivation by positive or negative role models: Regulatory focus determines who will best inspire us. Journal of Personality and Social Psychology, 83, 854-864.

Markus, H. R., \& Kitayama, S. (1991). Culture and the self: Implications for cognition, emotion, and motivation. Psychological Review, 98, 224-253.

Mauro, R., Sato, K., \& Tucker, J. (1992). The role of appraisal in human emotions: A crosscultural study. Journal of Personality and Social Psychology, 62, 301-317.

Meijiyasuda. (2009). Umare nenbetsu namae besuto 10 [Top 10 names by year of birth]. Retrieved from http://www.meijiyasuda.co.jp/profile/etc/ranking/ Mendoza-Denton, R., \& Mischel, W. (2007). Integrating system approaches to culture and 
personality: The cultural cognitive-affective processing system. In S. Kitayama \& D. Cohen (Eds.), Handbook of cultural psychology (pp. 175-195). New York, NY: Guilford Press.

Mesquita, B. (1993). Cultural variations in emotions: A comparative study of Dutch, Surinamese and Turkish people in the Netherlands (Unpublished doctoral dissertation). University of Amsterdam, Amsterdam, The Netherlands.

Mesquita, B. (2001). Emotions in collectivist and individualist contexts. Journal of Personality and Social Psychology, 80, 68-74.

Mesquita, B. (2010). Emoting: A contextualized process. In B. Mesquita, L. F. Barrett, \& E. R. Smith (Eds.), The mind in context (pp. 83-104). New York: Guilford Press.

Mesquita, B., Boiger, M., \& De Leersnyder, J. (2016). The cultural construction of emotions. Current Opinion in Psychology, 8, 31-36.

Mesquita, B., Boiger, M., \& De Leersnyder, J. (2017). Doing emotions: The role of culture in everyday emotions. European Review of Social Psychology, 28, 95-133.

Mesquita, B., \& Ellsworth, P. C. (2001). The role of culture in appraisal. In K. R. Scherer \& A. Schorr (Eds.), Appraisal processes in emotion: Theory, methods, research (pp. 233248). New York, NY: Oxford University Press.

Moors, A. (2014). Flavors of appraisal theories of emotion. Emotion Review, 6, 303-307.

Mu, Y., Kitayama, S., Han, S., \& Gelfand, M. J. (2015). How culture gets embrained: Cultural differences in event-related potentials of social norm violations. Proceedings of the National Academy of Sciences, 112. doi:10.1073/pnas.1509839112

Ortony, A., Clore, G. L., \& Collins, A. (1988). The cognitive structure of emotions. Cambridge, UK: Cambridge University Press. doi:10.2307/2074241

Oyserman, D., Coon, H. M., \& Kemmelmeier, M. (2002). Rethinking individualism and collectivism: Evaluation of theoretical assumptions and meta-analysis. Psychological 
Bulletin, 128, 3-72.

Park, J., Kitayama, S., Markus, H. R., Coe, C. L., Miyamoto, Y., Karasawa, M., ... Ryff, C. D. (2013). Social status and anger expression: The cultural moderation hypothesis. Emotion, 13, 1122-1131.

Roseman, I. J., Dhawan, N., Rettek, S. I., Naidu, R. K., \& Thapa, K. (1995). Cultural differences and cross-cultural similarities in appraisals and emotional responses. Journal of Cross-Cultural Psychology, 26, 23-48.

Scherer, K. R., \& Wallbott, H. G. (1994). Evidence for universality and cultural variation of differential emotion response patterning. Journal of Personality and Social Psychology, $66,310-328$.

Schwartz, S. H., \& Ros, M. (1995). Values in the West: A theoretical and empirical challenge to the individualism-collectivism cultural dimension. World Psychology, 1, 99-122.

Snibbe, A. C., \& Markus, H. R. (2005). You Can’t Always Get What You Want: Educational Attainment, Agency, and Choice, 88, 703-720.

Social Security Administration, \& Administration, S. S. (2009). Popular names by birth year. Retrieved from http://www.ssa.gov/OACT/babynames/

Spielberger, C. D., \& Sydeman, S. J. (1994). State-trait anxiety inventory and state-trait anger expression inventory. In M. E. Maruish (Ed.), The use of psychological tests for treatment planning and outcome assessment (pp. 292-321). Hillsdale, NJ: Erlbaum.

Tong, E. M. W. W., Bishop, G. D., Enkelmann, H. C., Why, Y. P., Diong, S. M., Ang, J., \& Khader, M. (2006). The role of the Big Five in appraisals. Personality and Individual Differences, 41, 513-523.

Tsai, J. L., Miao, F. F., Seppala, E., Fung, H. H., \& Yeung, D. Y. (2007). Influence and adjustment goals: Sources of cultural differences in ideal affect. Journal of Personality and Social Psychology, 92, 1102-17. 
Van der Ploeg, H. M., Defares, P. B., \& Spielberger, C. D. (1982). Zelf-analyse vragenlijst [Trait Anger Scale]. Lisse, The Netherlands: Swets \& Zeitlinger.

Vansteelandt, K., \& Van Mechelen, I. (2006). Individual differences in anger and sadness: in pursuit of active situational features and psychological processes. Journal of Personality, 74, 871-909.

Wallbott, H. G., \& Scherer, K. R. (1986). The antecedents of emotional experience. In K. R. Scherer, H. G. Wallbott, \& A. B. Summerfield (Eds.), Experiencing emotion: A crosscultural study (pp. 69-83). Cambridge, UK: Cambridge University Press. 


\section{Footnotes}

${ }^{1}$ We consider appraisals and action tendencies as descriptions of different aspects of emotional experience, as opposed to other theories which consider appraisal as the precursor of emotional experience and action tendencies as the consequence (see Moors, 2014). In our view, appraisal is no prerequisite for action tendencies. Rather, appraisals and action tendencies shed light on different aspects of emotional experience (see Barrett et al, 2007): Appraisals represent the interpretative aspects of emotional experience, and action tendencies the intentional aspects (Ellsworth, 2013; Frijda, 2007; Ortony, Clore, \& Collins, 1988). What we call "emotional experience" in the current paper, is the awareness of these different appraisals and action tendencies.

${ }^{2}$ We refrained from making specific predictions about the nature of cultural variation given the expected complexity in the "content" of the resulting anger and shame types. Making predictions would have meant to hypothesize about the kinds of situations that will likely be associated with different patterns of appraisals/action tendencies for different experience types, or about the appraisals/action tendencies that will likely show different patterns over situations for different experience types, and to then link differences between types to the cultural context. Because of the inductive scope and nature of our research - that is, both the stimulus material and the types of situated emotional experience were established empirically and from the ground up — we did not deem these kinds of predictions desirable. We also doubt that making systematic predictions would have been feasible, given the lack of previous research on situational variation in the appraisals/action tendencies of anger and shame across cultures.

${ }^{3}$ In both versions of the SEEQ, participants were asked to which extent they would feel each of a total of nine emotions; the eight emotions besides anger in the SEEQ-A and shame in the SEEQ-S were not included in the current analysis. 
${ }^{4}$ The CLASSI model described in Ceulemans and Van Mechelen (Ceulemans \& Van Mechelen, 2008) and Ceulemans et al. (Ceulemans et al., 2012) was originally developed for binary data. The CLASSI model that we used in the present study constitutes a refinement in that it can model interval-scaled rating data. This model yields two response typologies - one indicating those participants that share a similar pattern of emotion components across situations, and one indicating those participants that associate similar emotion components with the experience of anger and shame (intensity). For the purposes of the present paper, only the former response typology is reported. 


\section{Acknowledgments}

We thank Tom Wilderjans for his help with setting up the analyses on the highperformance computing cluster. We are also grateful to Shunta Maeda, Atsuko Tominaga, Naka Kitamura, Nozomu Shida, and Maria Almoite for their help in collecting the Japanese data. 
Table 1

Distribution of Anger Experience Types Across Participant's Cultural Backgrounds

\begin{tabular}{lllllll}
\hline & \multicolumn{2}{l}{ Three-type solution } & & \multicolumn{2}{l}{ Two-type solution } \\
\cline { 2 - 3 } & Type 1 & Type 2 & Type 3 & & Type 1 & Type 2 \\
\hline U.S. $(n=100)$ & $\mathbf{3 8 . 0 \%}$ & $22.0 \%$ & $40.0 \%$ & & $27.0 \%$ & $\mathbf{7 3 . 0 \%}$ \\
Japan $(n=111)$ & $9.0 \%$ & $\mathbf{9 0 . 1 \%}$ & $0.9 \%$ & & $\mathbf{9 6 . 4 \%}$ & $3.6 \%$ \\
Belgium $(n=211)$ & $45.0 \%$ & $3.8 \%$ & $\mathbf{5 1 . 2 \%}$ & & $6.2 \%$ & $\mathbf{9 3 . 8 \%}$ \\
\hline$\chi^{2}(4)$ & $260.54^{* * * *}$ & & & $264.45^{* * *}$ & \\
\hline
\end{tabular}

Note. Percentages are row-percentages. Culturally dominant cells in bold. ${ }^{* * *} p<.001$. 
Table 2

Distribution of Shame Experience Types Across Participant's Cultural Backgrounds

\begin{tabular}{llll}
\hline & Type 1 & Type 2 & Type 3 \\
\hline U.S. $(n=109)$ & $\mathbf{7 7 . 1 \%}$ & $2.8 \%$ & $20.2 \%$ \\
Japan $(n=113)$ & $7.1 \%$ & $\mathbf{9 1 . 2 \%}$ & $1.8 \%$ \\
Belgium $(n=239)$ & $32.6 \%$ & $2.9 \%$ & $\mathbf{6 4 . 4 \%}$ \\
\hline$\chi^{2}(4)$ & $437.89^{* * * *}$ & & \\
\hline
\end{tabular}

Note. Percentages are row-percentages. Culturally dominant cells in bold. ${ }^{* * *} p<.001$. 
Table 3

Significant Predictors of Anger and Shame Experience Typology (Three-Type Solutions)

\begin{tabular}{|c|c|c|c|}
\hline Effects & $d f$ & Anger & Shame \\
\hline Culture & 4 & $127.7^{* * * *}$ & $218.4^{* * *}$ \\
\hline Gender & 2 & $18.1^{* * *}$ & $9.7^{* *}$ \\
\hline SES & 8 & $22.8^{* *}$ & \\
\hline Agreeableness & 2 & & $7.2^{*}$ \\
\hline Individual Self & 2 & & $7.2^{*}$ \\
\hline
\end{tabular}

Note. $-2 \log$ likelihood ratio $\left(\chi^{2}\right)$ tests between the final and a reduced model for multinomial regressions predicting the induced three-type solutions. Entered predictors: Culture, gender, socioeconomic status, age, extraversion, agreeableness, conscientiousness, neuroticism, openness, collective self, relational self, individual self, promotion focus, prevention focus, anger/shame proneness and alexithymia. Only statistically significant effects $(p<.05)$ are shown. ${ }^{* * *} p<.001,{ }^{* *} p<.01,{ }^{*} p<.05$. 


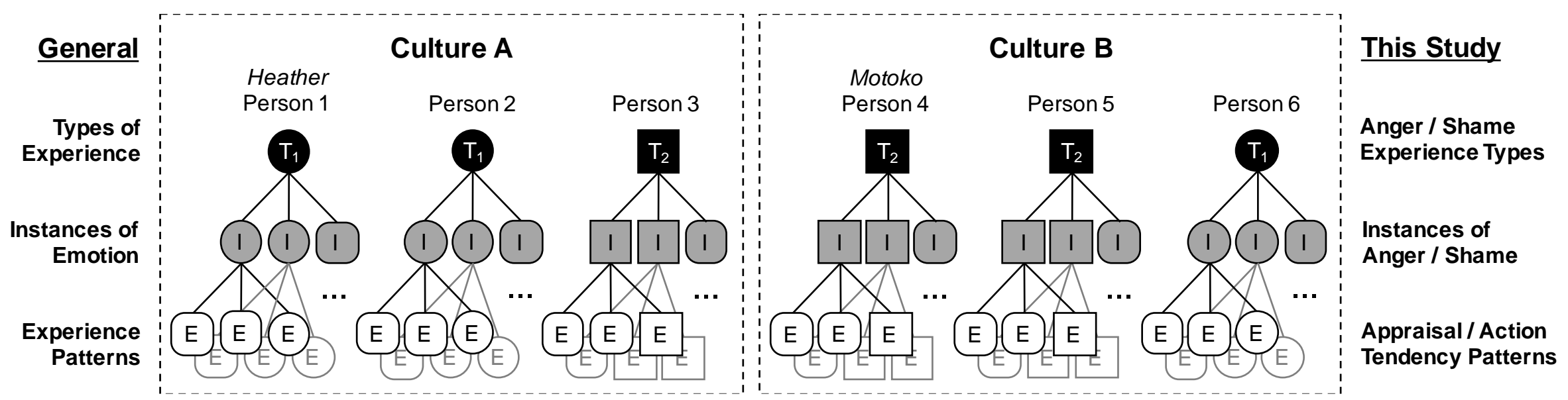

Figure 1. Distribution of the population of emotion instances for six exemplary participants across two cultures. Each participant belongs to one of two experience types. Experience types differ in their respective populations of emotion instances. Each emotion instance is described as a pattern of emotional experiences (here, appraisals and action tendencies). Squares and circles denote different, rounded squares shared instances, appraisals, or action tendencies between the experience types. 


\section{A. Other-blame}

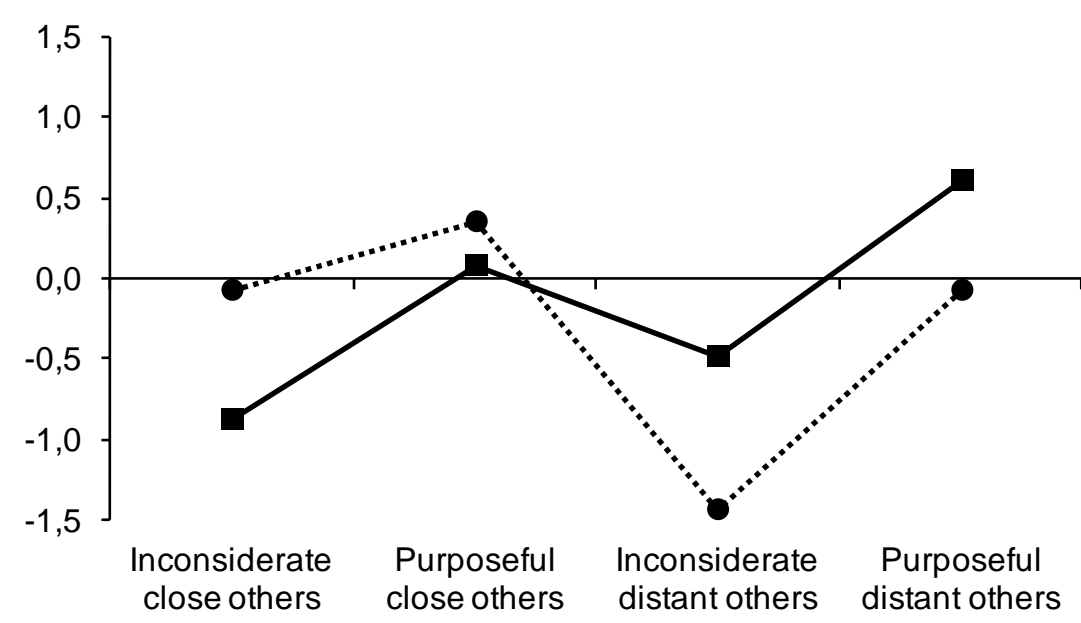

\section{B. Preoccupation}

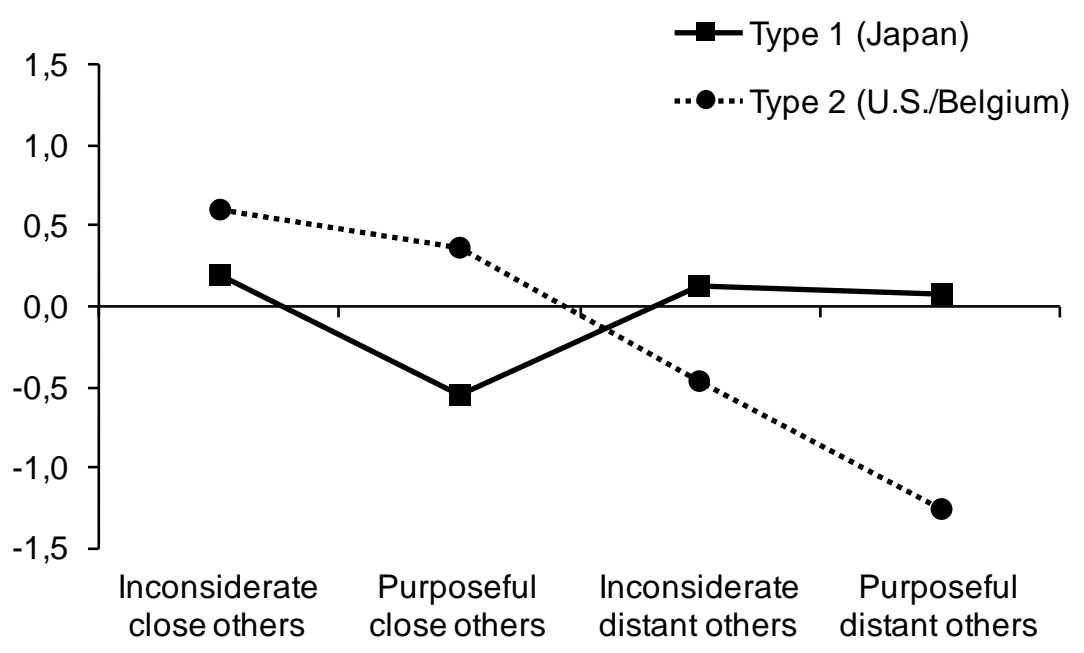

Figure 2. Intensity of anger responses (other-blame and preoccupation) that differed most across experience types by situation. For each situation type, the situation that afforded the most differences between types was chosen. 


\section{A. Relativizing}

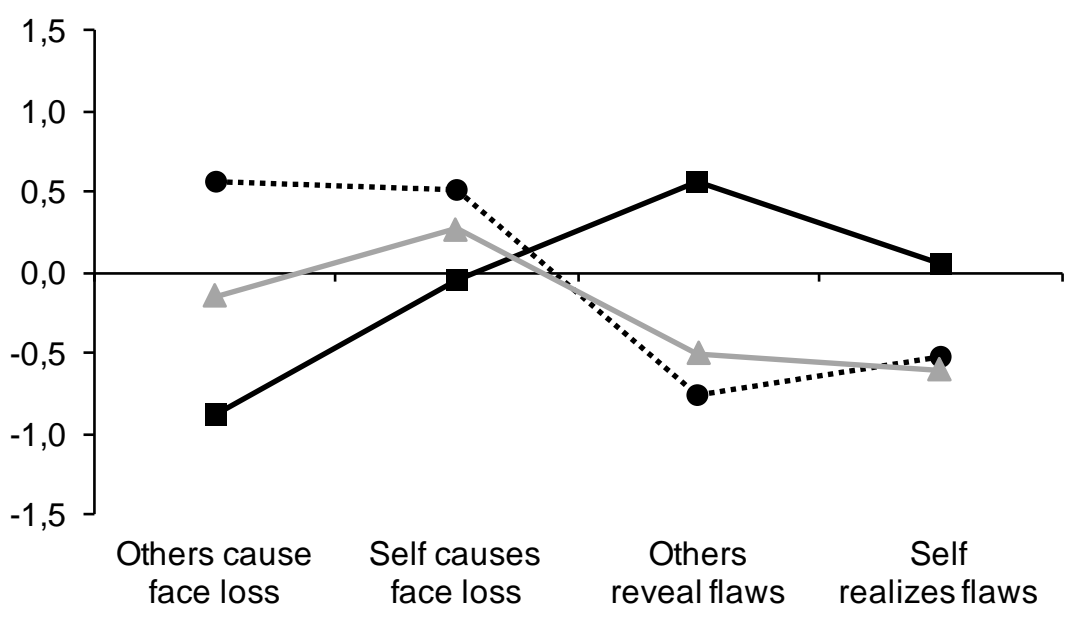

\section{B. Other-esteem}

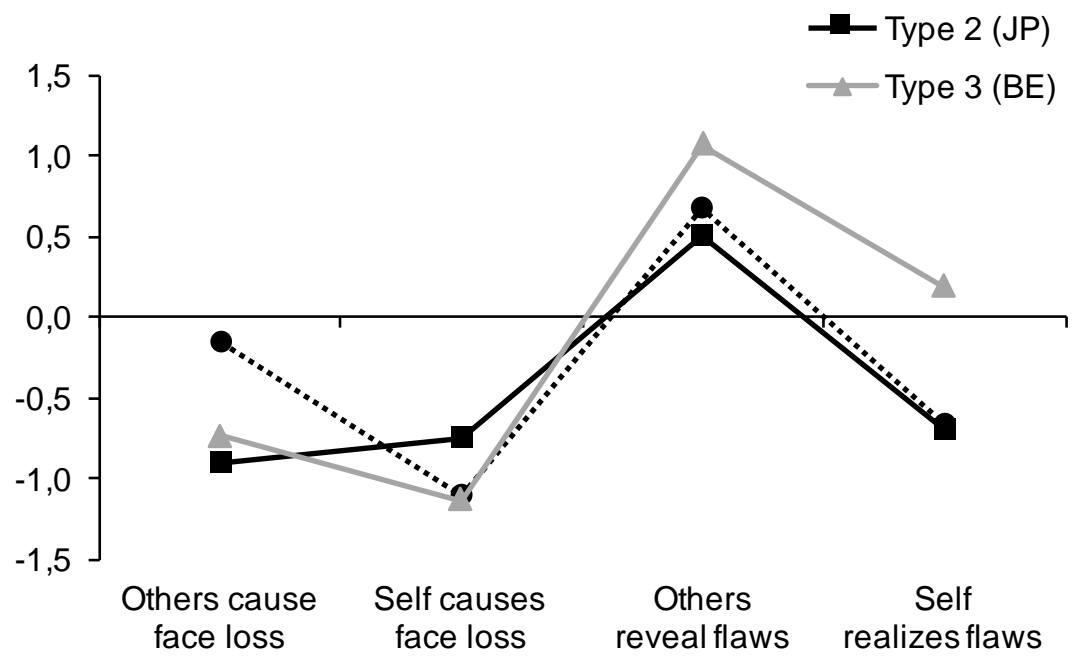

Figure 3. Intensity of shame responses (relativizing and other-esteem) that differed most across experience types by situation. For each situation type, the situation that afforded the most differences between types was chosen. 


\section{Appendix A}

\section{Situation Vignettes Included in the SEEQ}

Table A1

Anger Situation Vignettes

\begin{tabular}{|c|c|c|c|c|}
\hline $\begin{array}{c}\text { Short } \\
\text { description }\end{array}$ & Situation vignette & Origin & Dim. 1 & $\underset{2}{\operatorname{Dim} .}$ \\
\hline $\begin{array}{l}\text { Belated friend } \\
\text { (friend) }\end{array}$ & $\begin{array}{l}\text { Joshua and his friend had agreed to meet } \\
\text { right after school. Joshua took off as soon } \\
\text { as school had ended and hurried to his } \\
\text { friend's place. After } 20 \text { minutes of waiting, } \\
\text { his friend had still not shown up. }\end{array}$ & Japan & inconsiderate & close \\
\hline $\begin{array}{l}\text { Emails ignored } \\
\text { (club members) }\end{array}$ & $\begin{array}{l}\text { Michael was on the organizing committee } \\
\text { of a youth organization where most of the } \\
\text { other members were } 5-10 \text { years older than } \\
\text { him. When he sent an email concerning the } \\
\text { organization of a concert, none of the other } \\
\text { members replied. However, the emails sent } \\
\text { by the older members usually get instant } \\
\text { and positive responses. }\end{array}$ & Belgium & purposeful & close \\
\hline $\begin{array}{l}\text { Stairs collision } \\
\text { (strangers) }\end{array}$ & $\begin{array}{l}\text { Anthony and a friend were going upstairs } \\
\text { in a restaurant, when a large group of } \\
\text { people squeezed by on their way down. } \\
\text { One of them hollered at Anthony and his } \\
\text { friend "Hey, stop pushing us!". }\end{array}$ & Japan & purposeful & distant \\
\hline $\begin{array}{l}\text { Facebook attack } \\
\text { (strangers) }\end{array}$ & $\begin{array}{l}\text { Lauren is member of a local youth } \\
\text { organization. Some days ago, she saw that } \\
\text { someone started a Facebook group against } \\
\text { her organization, saying that they "suck". } \\
\text { The group is criticizing everything that } \\
\text { Lauren's organization does, and lots of } \\
\text { kids have already joined the group doing } \\
\text { the criticizing. }\end{array}$ & Belgium & purposeful & distant \\
\hline $\begin{array}{l}\text { Brags about } \\
\text { brother (father) }\end{array}$ & $\begin{array}{l}\text { Ryan went to a university away from home } \\
\text { and came to see his family over the } \\
\text { holidays. Whenever Ryan talked about } \\
\text { something he felt proud of, his father } \\
\text { changed the topic to his younger brother's } \\
\text { football career. }\end{array}$ & U.S. & purposeful & close \\
\hline $\begin{array}{l}\text { Fat in Florida } \\
\text { (grandmother) }\end{array}$ & $\begin{array}{l}\text { Jennifer was visiting her grandmother in } \\
\text { Florida together with her mother and two } \\
\text { of her friends. Her grandmother kept } \\
\text { suggesting that Jennifer was too fat and } \\
\text { that she was eating too much, despite the } \\
\text { fact that Jennifer is skinny. }\end{array}$ & U.S. & purposeful & close \\
\hline $\begin{array}{l}\text { Shared secrets } \\
\text { (best friend) }\end{array}$ & $\begin{array}{l}\text { David and Jessica were close friends who } \\
\text { shared everything. One day, David found } \\
\text { out that Jessica had shared some of his } \\
\text { personal stories with one of her friends. }\end{array}$ & Belgium & inconsiderate & close \\
\hline
\end{tabular}




\begin{tabular}{|c|c|c|c|c|}
\hline $\begin{array}{c}\text { Short } \\
\text { description }\end{array}$ & Situation vignette & Origin & Dim. 1 & $\underset{2}{\text { Dim. }}$ \\
\hline $\begin{array}{l}\text { Drinking party } \\
\text { (roommate) }\end{array}$ & $\begin{array}{l}\text { Kayla shared a room with another student. } \\
\text { One night Kayla came home to a big mess. } \\
\text { Her roommate had invited a bunch of } \\
\text { people to their room. They had been } \\
\text { drinking but obviously failed to clean up } \\
\text { after themselves. }\end{array}$ & U.S. & inconsiderate & distant \\
\hline $\begin{array}{l}\text { First sick, then } \\
\text { party } \\
\text { (boyfriend) }\end{array}$ & $\begin{array}{l}\text { Amber had been worried about her } \\
\text { boyfriend who was at home sick for the } \\
\text { last several days. The day he went back to } \\
\text { work he left her a voice-mail saying that he } \\
\text { would be home late because he was going } \\
\text { for drinks with his co-workers. }\end{array}$ & Japan & inconsiderate & close \\
\hline $\begin{array}{l}\text { Slow at ATM } \\
\text { (stranger) }\end{array}$ & $\begin{array}{l}\text { Christopher was in a hurry to withdraw } \\
\text { some cash. The person in front of him was } \\
\text { having trouble with the ATM, and he took } \\
\text { a very long time. }\end{array}$ & Japan & inconsiderate & distant \\
\hline $\begin{array}{l}\text { Needy student } \\
\text { (student) }\end{array}$ & $\begin{array}{l}\text { Amanda wanted to go home to study after } \\
\text { class. Another student from her year } \\
\text { walked up to her, asking if they could go } \\
\text { over today's lesson and practice together. } \\
\text { Amanda did not dare to say no and ended } \\
\text { up having no time to study herself. }\end{array}$ & Belgium & inconsiderate & distant \\
\hline $\begin{array}{l}\text { Rewrite paper } \\
\text { (teacher) }\end{array}$ & $\begin{array}{l}\text { One of Ashley's teachers returned the } \\
\text { class' written papers and announced that } \\
\text { everyone had to re-write their papers from } \\
\text { scratch because nobody had followed the } \\
\text { instructions of the assignment. }\end{array}$ & U.S. & purposeful & distant \\
\hline $\begin{array}{l}\text { Not available } \\
\text { after bad news } \\
\text { (boyfriend) }\end{array}$ & $\begin{array}{l}\text { Brittany had received some upsetting news } \\
\text { from her doctor. For two whole days, she } \\
\text { tried to tell her boyfriend about it, but he } \\
\text { was never available. }\end{array}$ & U.S. & inconsiderate & close \\
\hline $\begin{array}{l}\text { Chatting in the } \\
\text { back } \\
\text { (classmates) }\end{array}$ & $\begin{array}{l}\text { Kyle was determined to do well in a class } \\
\text { that was required for his major. He put in a } \\
\text { lot of work and tried to pay attention } \\
\text { during class. However, during the last class } \\
\text { session he kept being distracted by students } \\
\text { in the back chatting and cell phones going } \\
\text { off. }\end{array}$ & Japan & inconsiderate & distant \\
\hline $\begin{array}{l}\text { Ignored and } \\
\text { asocial } \\
\text { (flatmates) }\end{array}$ & $\begin{array}{l}\text { Sarah was sitting in her dorm room } \\
\text { studying, when a group of people passed in } \\
\text { the hallway who were asking around if } \\
\text { people want to join for a party. They did } \\
\text { not knock on her door and she heard them } \\
\text { say that it is not worth asking her, because } \\
\text { she was anyways always a loner. }\end{array}$ & Belgium & purposeful & close \\
\hline
\end{tabular}

Note. Dim. 1 = Location on anger situation dimension 1 (intentionality, ranging from purposeful to inconsiderate). Dim. 2 = Location on anger situation dimension 2 (closeness, ranging from close to distant others). 
Table A2

Shame Situation Vignettes

\begin{tabular}{|c|c|c|c|c|}
\hline $\begin{array}{c}\text { Short } \\
\text { description }\end{array}$ & Situation vignette & Origin & Dim. 1 & Dim. 2 \\
\hline $\begin{array}{l}\text { Phone mum } \\
\text { (mother) }\end{array}$ & $\begin{array}{l}\text { David had a long and busy week at college. } \\
\text { When he came home to his dorm room, he found } \\
\text { a message from his mom. He realized it had been } \\
\text { weeks since they had talked. }\end{array}$ & U.S. & $\begin{array}{l}\text { other } \\
\text { agency }\end{array}$ & $\begin{array}{l}\text { personal } \\
\text { flaws }\end{array}$ \\
\hline $\begin{array}{l}\text { Other knows } \\
\text { better (junior) }\end{array}$ & $\begin{array}{l}\text { Joshua participated in a study group to prepare } \\
\text { for an exam. He was one of the more advanced } \\
\text { students of the group. When Joshua expressed } \\
\text { what he did not understand about the material, a } \\
\text { student much more junior than Joshua readily } \\
\text { explained it to him. }\end{array}$ & Japan & $\begin{array}{c}\text { self } \\
\text { agency }\end{array}$ & $\begin{array}{l}\text { personal } \\
\text { flaws }\end{array}$ \\
\hline $\begin{array}{l}\text { Misunderstood } \\
\text { lyrics (friend) }\end{array}$ & $\begin{array}{l}\text { Brandon introduced his friend John to his favorite } \\
\text { album. Later John told Brandon how much he } \\
\text { liked the music. Over the course of their } \\
\text { conversation, Brandon realized that he had } \\
\text { always completely misunderstood the lyrics to } \\
\text { the lead song on the album. }\end{array}$ & Japan & $\begin{array}{c}\text { self } \\
\text { agency }\end{array}$ & $\begin{array}{l}\text { public } \\
\text { face }\end{array}$ \\
\hline $\begin{array}{l}\text { Unable to } \\
\text { answer } \\
\text { (classmates) }\end{array}$ & $\begin{array}{l}\text { A group of students were giving a presentation in } \\
\text { one of Michael's classes. Michael did not pay } \\
\text { attention because class was almost over. After } \\
\text { they finished, the professor asked Michael to } \\
\text { summarize their points. He could not say } \\
\text { anything and everybody was staring at him. }\end{array}$ & Belgium & $\begin{array}{l}\text { other } \\
\text { agency }\end{array}$ & $\begin{array}{l}\text { public } \\
\text { face }\end{array}$ \\
\hline $\begin{array}{l}\text { No more } \\
\text { contact (best } \\
\text { friend) }\end{array}$ & $\begin{array}{l}\text { Emily and Julia were best friends for many years. } \\
\text { However, one day Julia just stopped talking to } \\
\text { Emily without ever giving any reason. Despite } \\
\text { Emily's many attempts to get back in contact, } \\
\text { Julia kept refusing to talk to Emily. }\end{array}$ & U.S. & $\begin{array}{l}\text { other } \\
\text { agency }\end{array}$ & $\begin{array}{l}\text { personal } \\
\text { flaws }\end{array}$ \\
\hline $\begin{array}{l}\text { Confused } \\
\text { customer } \\
\text { (stranger) }\end{array}$ & $\begin{array}{l}\text { Sarah went shopping with her boyfriend. Sarah } \\
\text { asked a sales person if it would be okay for her } \\
\text { boyfriend to try on some pants. Her boyfriend } \\
\text { immediately pointed out to her that the person } \\
\text { she had asked was a customer rather than a sales } \\
\text { person. }\end{array}$ & Japan & $\begin{array}{c}\text { self } \\
\text { agency }\end{array}$ & $\begin{array}{l}\text { public } \\
\text { face }\end{array}$ \\
\hline $\begin{array}{l}\text { Late for class } \\
\text { (classmates) }\end{array}$ & $\begin{array}{l}\text { Jessica had two overlapping classes and was } \\
\text { therefore too late for her second class. The } \\
\text { professor complained that she was late again and } \\
\text { the entire room was looking at her. }\end{array}$ & Belgium & $\begin{array}{l}\text { other } \\
\text { agency }\end{array}$ & $\begin{array}{l}\text { public } \\
\text { face }\end{array}$ \\
\hline $\begin{array}{l}\text { Lost computer } \\
\text { tournament } \\
\text { (friends) }\end{array}$ & $\begin{array}{l}\text { Christopher was participating at a large computer } \\
\text { game competition with other members of his } \\
\text { gaming team. He had told all of his friends that } \\
\text { they would easily win the competition. They } \\
\text { ended up losing big time. }\end{array}$ & Belgium & $\begin{array}{c}\text { self } \\
\text { agency }\end{array}$ & $\begin{array}{l}\text { personal } \\
\text { flaws }\end{array}$ \\
\hline $\begin{array}{l}\text { Undress at spa } \\
\text { (friends) }\end{array}$ & $\begin{array}{l}\text { Lauren was on a trip with some of her female } \\
\text { friends. One of the highlights of the trip was a }\end{array}$ & Japan & $\begin{array}{l}\text { other } \\
\text { agency }\end{array}$ & $\begin{array}{l}\text { public } \\
\text { face }\end{array}$ \\
\hline
\end{tabular}
visit to a spa. At the spa, Lauren had to undress in front of all her friends. 


\begin{tabular}{|c|c|c|c|c|}
\hline $\begin{array}{c}\text { Short } \\
\text { description }\end{array}$ & Situation vignette & Origin & Dim. 1 & Dim. 2 \\
\hline $\begin{array}{l}\text { Graduation } \\
\text { disappointment } \\
\text { (mother) }\end{array}$ & $\begin{array}{l}\text { On graduation day, Elizabeth's mom told her that } \\
\text { she was not proud of Elizabeth. The mother } \\
\text { explained that Elizabeth had not lived up to her } \\
\text { expectations. }\end{array}$ & U.S. & $\begin{array}{l}\text { other } \\
\text { agency }\end{array}$ & $\begin{array}{l}\text { personal } \\
\text { flaws }\end{array}$ \\
\hline $\begin{array}{l}\text { Forgotten } \\
\text { evening } \\
\text { (boyfriend) }\end{array}$ & $\begin{array}{l}\text { Ashley had gone out with a couple of friends. } \\
\text { When she got home she realized that she forgot } \\
\text { to tell her boyfriend, who had stayed home and } \\
\text { was waiting for her. }\end{array}$ & Belgium & $\begin{array}{l}\text { other } \\
\text { agency }\end{array}$ & $\begin{array}{l}\text { personal } \\
\text { flaws }\end{array}$ \\
\hline $\begin{array}{l}\text { Crying on } \\
\text { phone } \\
\text { (girlfriend) }\end{array}$ & $\begin{array}{l}\text { During a phone conversation, Ryan and his } \\
\text { girlfriend Rebecca got into a fight. Things got out } \\
\text { of hand, and Ryan started to cry and hung up. } \\
\text { The next day during lunch break, Rebecca told } \\
\text { other people at school that Ryan had started } \\
\text { crying on the phone. }\end{array}$ & U.S. & $\begin{array}{l}\text { other } \\
\text { agency }\end{array}$ & $\begin{array}{l}\text { public } \\
\text { face }\end{array}$ \\
\hline $\begin{array}{l}\text { Mediation } \\
\text { awry (juniors) }\end{array}$ & $\begin{array}{l}\text { Matthew tried to settle a dispute between two } \\
\text { lower classmen. However, he failed to strike the } \\
\text { right note and his attempts at mediation only } \\
\text { made things worse. }\end{array}$ & Japan & $\begin{array}{c}\text { self } \\
\text { agency }\end{array}$ & $\begin{array}{l}\text { personal } \\
\text { flaws }\end{array}$ \\
\hline $\begin{array}{l}\text { No money for } \\
\text { car bill (clerk) }\end{array}$ & $\begin{array}{l}\text { When Robert picked his car up from the garage, } \\
\text { he realized that he did not have enough money to } \\
\text { pay the bill. }\end{array}$ & U.S. & $\begin{array}{c}\text { self } \\
\text { agency }\end{array}$ & $\begin{array}{l}\text { public } \\
\text { face }\end{array}$ \\
\hline $\begin{array}{l}\text { Chewing gum } \\
\text { chair } \\
\text { (classmates) }\end{array}$ & $\begin{array}{l}\text { Andrew sat down on the last empty spot in class } \\
\text { when he realized that there was something sticky } \\
\text { on his chair. The other students around him } \\
\text { started looking and laughing at him because he } \\
\text { had just sat on a chewing gum, which is now } \\
\text { sticking to his pants. }\end{array}$ & Belgium & $\begin{array}{l}\text { other } \\
\text { agency }\end{array}$ & $\begin{array}{l}\text { public } \\
\text { face }\end{array}$ \\
\hline
\end{tabular}

Note. Dim. 1 = Location on shame situation dimension 1 (agency, ranging from other-agency to selfagency). Dim. 2 = Location on situation dimension 2 (self-violations involved, raning from public face loss to revelation of personal flaws). 


\section{Appendix B: Reduction of Emotion Components in the SEEQ}

Table B1

Simultaneous Component Analysis of Anger Appraisals

\begin{tabular}{|c|c|c|c|}
\hline \multirow[b]{2}{*}{ Appraisals } & \multicolumn{3}{|c|}{ Components } \\
\hline & Other-blame & Self-blame & $\begin{array}{c}\text { Goal- } \\
\text { blockage }\end{array}$ \\
\hline ...perceive $[\ldots]$ 's act as inappropriate & .86 & .08 & .13 \\
\hline ...feel that $[\ldots]$ is responsible for what happened & .80 & -.03 & .07 \\
\hline ...consider what happened to me as unfair & .74 & .16 & .33 \\
\hline $\begin{array}{l}\text {... focus on what I should have done to avoid the } \\
\text { situation }\end{array}$ & .07 & .93 & .18 \\
\hline$\ldots$ feel that $[\ldots]$ is in control of the situation & .42 & .17 & .51 \\
\hline $\begin{array}{l}\text {...feel that there are obstacles between me and } \\
\text { getting what I want }\end{array}$ & .09 & .14 & .89 \\
\hline ...perceive the situation as serious & - & - & - \\
\hline ...perceive the situation as unpleasant & - & - & - \\
\hline
\end{tabular}

Note. Clusterwise simultaneous component analysis. The two bottom items were excluded from the analysis because of cross-loadings. One-cluster solution explained $71.0 \%$ variance (orthogonal rotation). Variance explained per cultural group: U.S. $=71.3 \%$, Japan $=66.3 \%$, Belgium $=73.8 \%$. Component 2 has been multiplied with -1 for interpretability.

Table B2

Simultaneous Component Analysis of Anger Action Tendencies

\begin{tabular}{|c|c|c|c|}
\hline \multirow[b]{2}{*}{ Action Tendencies } & \multicolumn{3}{|c|}{ Components } \\
\hline & Aggression & Preoccupation & Non-action \\
\hline ...feel like shouting at $[\ldots]$ & .75 & .28 & -.08 \\
\hline$\ldots$ want to give $[\ldots]$ a piece of my mind & .73 & .14 & -.10 \\
\hline ...feel like hurting $[\ldots]$ & .72 & .22 & .10 \\
\hline $\begin{array}{l}\text {...feel that being angry is justified by what } \\
\text { happened }\end{array}$ & .66 & .39 & -.15 \\
\hline ...try to be patient with $[\ldots]$ & -.53 & .04 & .38 \\
\hline ... be unable to concentrate on anything else & .24 & .73 & -.05 \\
\hline ...feel paralyzed or frozen & .23 & 63 & .15 \\
\hline ...want the situation to be different or not to exist & .08 & .78 & -.13 \\
\hline ...deliberately do nothing & -.09 & -.05 & .87 \\
\hline
\end{tabular}

Note. Clusterwise simultaneous component analysis. One-cluster solution explained $59.0 \%$ variance (orthogonal rotation). Variance explained per cultural group: U.S. $=56.8 \%$, Japan $=52.4 \%$, Belgium $=$ $63.3 \%$. Component 2 has been multiplied with -1 for interpretability. 
Table B3

Simultaneous Component Analysis of Shame Appraisals

\begin{tabular}{|c|c|c|c|}
\hline \multirow[b]{2}{*}{ Appraisals } & \multicolumn{3}{|c|}{ Components } \\
\hline & Other-esteem & Relativizing & Self-esteem \\
\hline ...focus on what $[\ldots]$ is thinking of me & .84 & .09 & .10 \\
\hline $\begin{array}{l}\text {...feel that the event decreased }[\ldots] \text { 's respect for } \\
\text { me }\end{array}$ & .81 & -.02 & .28 \\
\hline ...feel that I failed in terms of $[\ldots]$ 's expectations & .73 & -.11 & .40 \\
\hline ...try not to make a whole lot out of the situation & .00 & .88 & .06 \\
\hline ...blame myself for the outcome of the situation & .48 & -.04 & .68 \\
\hline ...think "I was clumsy" & .16 & .12 & .85 \\
\hline ...perceive the situation as serious & - & - & - \\
\hline ...perceive the situation as unpleasant & - & - & - \\
\hline
\end{tabular}

Note. Clusterwise simultaneous component analysis. The two bottom items were excluded from the analysis because of cross-loadings. One-cluster solution explained $73.8 \%$ variance (orthogonal rotation). Variance explained per cultural group: $\mathrm{US}=73.4 \%$, Japan $=72.5 \%$, Belgium $=74.4 \%$.

Table B4

Simultaneous Component Analysis of Shame Action Tendencies

\begin{tabular}{|c|c|c|c|c|}
\hline \multirow[b]{2}{*}{ Action Tendencies } & \multicolumn{4}{|c|}{ Components } \\
\hline & Avoidance & Composure & Patience & Apologizing \\
\hline ...feel like crying & .81 & -.06 & .02 & .08 \\
\hline $\begin{array}{l}\text {... want the situation to be different or not to } \\
\text { exist }\end{array}$ & .69 & .34 & .14 & .33 \\
\hline $\begin{array}{l}\text {...feel like withdrawing from the whole } \\
\text { situation }\end{array}$ & .61 & .48 & .14 & .16 \\
\hline $\begin{array}{l}\text {... feel like making sure a similar situation will } \\
\text { be avoided in the future }\end{array}$ & .58 & .31 & .16 & .49 \\
\hline ...blush & 18 & .78 & -.10 & .14 \\
\hline ...try not to feel ashamed & .02 & .66 & .30 & -.14 \\
\hline ...try not to show $[\ldots]$ how I feel & .44 & .43 & .36 & -.38 \\
\hline ...try to be patient with the situation & .10 & .08 & .81 & .19 \\
\hline ...feeling like apologizing to $[\ldots]$ & .25 & -.04 & .17 & .80 \\
\hline
\end{tabular}

Note. Clusterwise simultaneous component analysis. One-cluster solution explained $67.6 \%$ variance (orthogonal rotation). Variance explained per cultural group: US $=66.1 \%$, Japan $=68.6 \%$, Belgium $=$ $67.8 \%$. Components 3 and 4 have been multiplied with -1 for interpretability. 


\section{Appendix C: Patterns of Emotional Experience by Induced Experience Types}

Table C1

Anger Appraisals and Action Tendencies Across Situations by Experience Type

\begin{tabular}{|c|c|c|c|c|c|c|c|c|c|c|c|c|c|}
\hline \multirow[b]{2}{*}{ Short Description } & \multicolumn{6}{|c|}{ Type 1 (Dominant in Japan) } & \multicolumn{6}{|c|}{ Type 2 (Dominant in U.S./Belgium) } & \multirow[b]{2}{*}{ 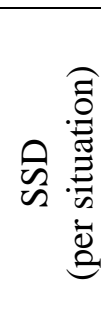 } \\
\hline & 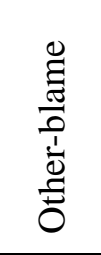 & 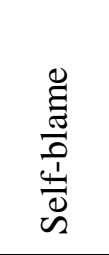 & 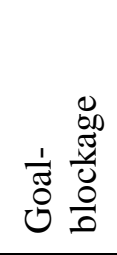 & 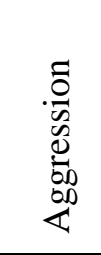 & 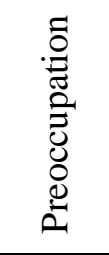 & 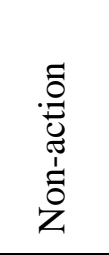 & 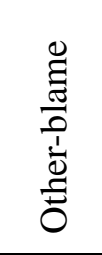 & 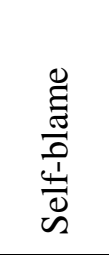 & 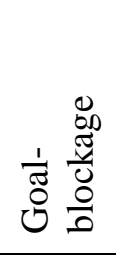 & $\begin{array}{l}\tilde{0} \\
.0 \\
0 \\
0 \\
0 \\
00 \\
0\end{array}$ & 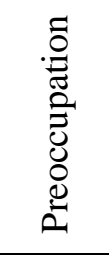 & 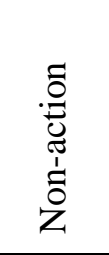 & \\
\hline Belated friend (friend) & 0.02 & -0.09 & -0.31 & -0.21 & -0.13 & -0.27 & -0.01 & -0.43 & -0.44 & -0.29 & -0.16 & -0.10 & 0.17 \\
\hline Emails ignored (club members) & 0.27 & 0.29 & 0.59 & 0.03 & 0.29 & -0.26 & 0.13 & -0.05 & 0.82 & 0.01 & 0.18 & -0.08 & 0.23 \\
\hline Stairs collision (strangers) & 0.61 & -0.09 & -0.64 & 0.42 & 0.08 & 0.36 & -0.08 & -0.37 & -1.10 & 0.46 & -1.26 & 0.31 & 2.57 \\
\hline Facebook attack (strangers) & -0.21 & 0.33 & 0.29 & 0.39 & 0.49 & -0.20 & 0.14 & 0.19 & 0.52 & 0.72 & 0.16 & -0.28 & 0.42 \\
\hline Brags about brother (father) & 0.20 & -0.46 & 0.10 & 0.16 & -0.37 & 0.35 & 0.38 & -0.31 & 0.61 & 0.41 & 0.48 & 0.08 & 1.17 \\
\hline Fat in Florida (grandmother) & 0.08 & -0.55 & -0.76 & -0.06 & -0.54 & 0.52 & 0.34 & -0.12 & -0.46 & -0.15 & 0.36 & 0.27 & 1.22 \\
\hline Shared secrets (best friend) & 0.73 & 0.42 & -0.18 & 0.88 & 0.52 & -0.29 & 1.12 & 0.40 & -0.24 & 1.03 & 0.46 & -0.41 & 0.20 \\
\hline Drinking party (roommate) & 0.81 & 0.09 & -0.24 & 0.84 & -0.13 & -0.30 & 0.52 & -0.46 & -0.80 & 0.06 & -0.63 & -0.23 & 1.56 \\
\hline First sick, then party (boyfriend) & -0.46 & -0.51 & -0.60 & -0.11 & -0.72 & 0.21 & -0.04 & -0.44 & -0.45 & -0.10 & -0.36 & 0.08 & 0.35 \\
\hline Slow at ATM (stranger) & -0.49 & -0.24 & 0.39 & -0.74 & 0.13 & 0.44 & -1.43 & -0.41 & -0.09 & -1.04 & -0.46 & 0.73 & 1.67 \\
\hline Needy student (student) & -0.96 & 0.29 & 0.29 & -0.77 & -0.23 & 0.14 & -1.44 & 0.47 & 0.14 & -1.08 & -0.35 & 0.23 & 0.40 \\
\hline Rewrite paper (teacher) & -0.39 & 0.42 & 0.57 & -0.59 & 0.07 & -0.11 & -0.12 & 0.74 & 0.31 & -0.16 & 0.21 & -0.21 & 0.46 \\
\hline Not available after bad news (boyfriend) & -0.87 & -0.32 & 0.25 & -0.24 & 0.20 & -0.48 & -0.08 & -0.10 & 0.48 & -0.21 & 0.60 & -0.49 & 0.89 \\
\hline Chatting in the back (classmates) & 0.82 & -0.07 & 0.41 & 0.71 & 0.60 & 0.10 & 0.26 & -0.13 & 0.60 & 0.51 & 0.12 & 0.07 & 0.62 \\
\hline Ignored and asocial (flatmates) & -0.15 & 0.50 & -0.16 & -0.13 & 0.66 & 0.65 & 0.32 & 0.96 & 0.13 & 0.32 & 0.98 & 0.53 & 0.84 \\
\hline SSD (per component) & 3.48 & 1.27 & 1.52 & 1.43 & 4.71 & 0.36 & 3.48 & 1.27 & 1.52 & 1.43 & 4.71 & 0.36 & \\
\hline
\end{tabular}

Note. Values are averages of person-centered component scores across participants of the same experience type. Highlighted cells show those combinations of situations and appraisals/action tendencies for which the squared difference between the two types was above the mean. SSD = Sum of Squared Differences between types. 
Table C2

Shame Appraisals and Action Tendencies Across Situations by Experience Type

\begin{tabular}{|c|c|c|c|c|c|c|c|c|c|c|c|c|c|c|}
\hline \multirow[b]{2}{*}{ Short Description } & \multicolumn{7}{|c|}{ Type 1 (Dominant in U.S.) } & \multicolumn{7}{|c|}{ Type 2 (Dominant in Japan) } \\
\hline & 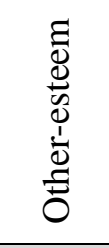 & 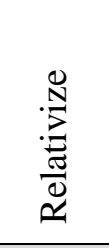 & 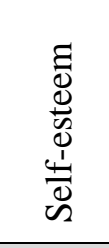 & 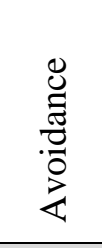 & 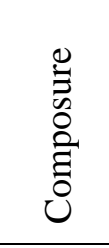 & 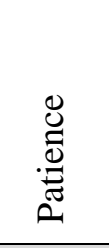 & 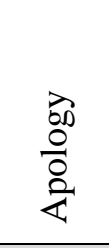 & 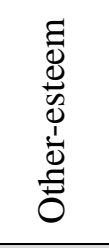 & $\frac{\stackrel{\mathscr{N}}{\mathbb{N}}}{\frac{\vec{J}}{\mathscr{Q}}}$ & 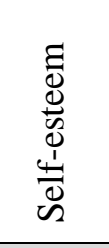 & 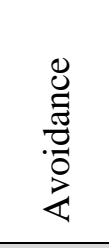 & 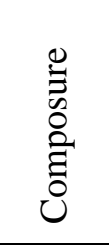 & 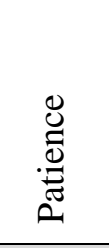 & $\begin{array}{l}\text { 盛 } \\
\frac{0}{0} \\
\frac{2}{2}\end{array}$ \\
\hline Phone mum (mother) & -0.66 & -0.52 & -0.23 & -0.52 & -1.20 & 0.07 & 0.53 & -0.69 & 0.05 & -0.06 & -0.71 & -1.04 & -0.43 & 0.10 \\
\hline Other knows better (junior) & -0.53 & 0.08 & -0.50 & -0.71 & -0.46 & 0.35 & -0.81 & 0.05 & -0.52 & -0.02 & -0.11 & 0.24 & 0.21 & -0.46 \\
\hline Misunderstood lyrics (friend) & -1.24 & 0.15 & -0.29 & -1.11 & -0.47 & -0.35 & -0.79 & -0.91 & -0.42 & -0.35 & -0.78 & -0.16 & -0.29 & -0.55 \\
\hline Unable to answer (classmates) & 0.53 & 0.01 & 0.52 & 0.34 & 0.70 & -0.22 & 0.17 & 0.84 & -0.20 & 0.40 & 0.43 & 0.75 & 0.18 & 0.58 \\
\hline No more contact (best friend) & 0.67 & -0.75 & -0.55 & 0.89 & -1.11 & 0.12 & 0.11 & 0.51 & 0.57 & -0.29 & 0.68 & -1.10 & 0.09 & -0.07 \\
\hline Confused customer (stranger) & -1.10 & 0.52 & 0.40 & -0.96 & 0.43 & -0.43 & -0.13 & -0.75 & -0.04 & -0.06 & -0.58 & 0.82 & -0.60 & 0.16 \\
\hline Late for class (classmates) & 0.18 & 0.19 & -0.23 & 0.04 & 0.74 & 0.21 & 0.20 & -0.12 & 0.38 & -0.50 & 0.01 & 0.47 & 0.22 & -0.39 \\
\hline Lost computer tournament (friends) & 0.31 & 0.31 & 0.12 & -0.21 & 0.12 & 0.15 & 0.45 & 0.62 & -0.49 & 0.25 & 0.14 & 0.29 & 0.04 & 0.34 \\
\hline Undress at spa (friends) & -0.16 & 0.56 & -1.35 & -0.44 & 0.57 & 0.01 & -0.86 & -0.90 & -0.88 & -1.14 & -1.37 & -0.50 & -0.33 & -1.07 \\
\hline Graduation disappointment (mother) & 1.06 & -0.37 & 0.42 & 1.06 & -0.20 & -0.27 & 0.25 & 0.94 & -0.35 & 0.29 & 0.90 & -0.45 & 0.42 & 0.02 \\
\hline Forgotten evening (boyfriend) & 0.63 & -0.12 & 0.66 & 0.08 & -0.35 & 0.04 & 1.36 & 1.08 & 0.13 & 0.59 & 0.20 & -0.66 & 0.09 & 1.68 \\
\hline Crying on phone (girlfriend) & 0.26 & -0.11 & -0.66 & 0.93 & 0.22 & -0.09 & -0.97 & 0.35 & 0.60 & -0.68 & 0.74 & 0.63 & 0.08 & -0.72 \\
\hline Mediation awry (juniors) & 0.02 & -0.18 & 0.26 & 0.00 & -0.05 & 0.36 & 0.34 & -0.15 & 0.41 & 1.36 & 0.26 & -0.33 & 0.41 & 0.40 \\
\hline No money for car bill (clerk) & 0.20 & -0.05 & 0.82 & 0.08 & 0.51 & 0.24 & 0.87 & -0.62 & 0.04 & 0.47 & -0.24 & 0.53 & -0.03 & 0.74 \\
\hline Chewing gum chair (classmates) & -0.14 & 0.26 & 0.31 & 0.49 & 0.65 & -0.10 & -0.68 & -0.31 & 0.71 & -0.33 & 0.67 & 0.84 & -0.13 & -0.80 \\
\hline SSD (per component) & 3.63 & 8.40 & 3.01 & 3.35 & 3.24 & 1.97 & 2.03 & 3.63 & 8.40 & 3.01 & 3.35 & 3.24 & 1.97 & 2.03 \\
\hline
\end{tabular}

Note. Values are averages of person-centered component scores across participants of the same experience type. Highlighted cells show those combinations of situations and appraisals/action tendencies for which the squared difference between the smallest and largest value across the three types was above the mean. $\mathrm{SSD}=$ Sum of Squared Differences between types. 


\section{Table C2}

Shame Appraisals and Action Tendencies Across Situations by Experience Type (Continued)

\begin{tabular}{|c|c|c|c|c|c|c|c|c|}
\hline \multirow[b]{2}{*}{ Short Situation Description } & \multicolumn{7}{|c|}{ Type 3 (Dominant in Belgium) } & \multirow[b]{2}{*}{ 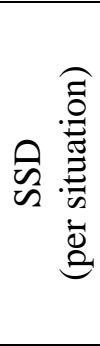 } \\
\hline & 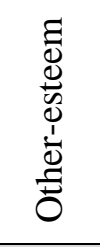 & 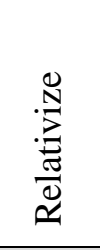 & 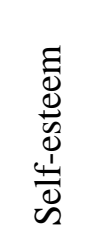 & 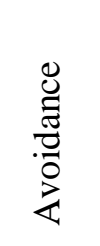 & $\begin{array}{l}0 \\
\vdots \\
0 \\
0 \\
0 \\
0 \\
0\end{array}$ & 导 & $\begin{array}{l}\text { के० } \\
\frac{0}{0} \\
\frac{0}{2}\end{array}$ & \\
\hline Phone mum (mother) & 0.19 & -0.60 & 0.30 & 0.39 & -0.76 & 0.14 & 0.86 & 3.78 \\
\hline Other knows better (junior) & -0.35 & 0.35 & -0.13 & -0.47 & -0.16 & 0.42 & -0.58 & 2.34 \\
\hline Misunderstood lyrics (friend) & -0.89 & 0.08 & -0.27 & -0.77 & -0.36 & -0.18 & -0.62 & 0.75 \\
\hline Unable to answer (classmates) & 0.49 & 0.41 & 0.64 & 0.31 & 1.03 & -0.12 & 0.11 & 1.06 \\
\hline No more contact (best friend) & 1.07 & -0.50 & -0.55 & 1.05 & -0.94 & 0.48 & 0.03 & 2.47 \\
\hline Confused customer (stranger) & -1.13 & 0.27 & 0.41 & -0.89 & 0.24 & -0.58 & -0.20 & 1.32 \\
\hline Late for class (classmates) & -0.11 & 0.56 & -0.54 & -0.17 & 0.81 & 0.04 & 0.14 & 0.86 \\
\hline Lost computer tournament (friends) & 0.22 & 0.02 & 0.09 & 0.03 & 0.09 & -0.02 & 0.08 & 1.15 \\
\hline Undress at spa (friends) & -0.73 & -0.14 & -1.33 & -0.94 & -0.57 & -0.72 & -0.94 & 5.41 \\
\hline Graduation disappointment (mother) & 0.79 & -0.12 & 0.34 & 0.84 & -0.28 & 0.07 & 0.04 & 0.79 \\
\hline Forgotten evening (boyfriend) & 0.84 & -0.54 & 0.73 & 0.21 & -0.29 & -0.10 & 1.54 & 0.96 \\
\hline Crying on phone (girlfriend) & 0.25 & 0.03 & -0.79 & 0.89 & 0.26 & -0.13 & -0.92 & 0.84 \\
\hline Mediation awry (juniors) & -0.13 & -0.21 & 0.18 & -0.03 & -0.14 & 0.44 & 0.11 & 2.06 \\
\hline No money for car bill (clerk) & -0.32 & -0.08 & 0.57 & -0.18 & 0.30 & 0.20 & 0.78 & 1.05 \\
\hline Chewing gum chair (classmates) & -0.21 & 0.44 & 0.18 & 0.45 & 0.72 & -0.17 & -0.60 & 0.77 \\
\hline SSD (per component) & 3.63 & 8.40 & 3.01 & 3.35 & 3.24 & 1.97 & 2.03 & \\
\hline
\end{tabular}

